\title{
新型大环芳烃的研究进展
}

\author{
李晶 $a, b$ 韩 莹 ${ }^{a}$ 陈传峰*, $a, b$ \\ ( ${ }^{a}$ 中国科学院化学研究所 分子识别与功能院重点实验室 北京 100190) \\ ${ }^{b}$ 中国科学院大学 北京 100049)
}

\begin{abstract}
摘要 杯芳烃、柱芳烃及其类似物均由羟基或烷氧基取代的芳环通过亚甲基或次甲基桥连而形成的大环分子, 统称为 大环芳烃. 大环芳烃由于具有结构特殊、易于合成与衍生化、富电子空腔等特点以及其在超分子化学等领域中的广泛 应用, 因而一直引起人们极大的关注与兴趣, 成为了最重要和研究最多的合成大环主体分子之一. 近年来, 随着大环 与超分子化学的快速发展, 除杯芳烃、柱芳烃等经典大环芳烃之外, 各种不同类型的具有新颖结构的大环芳烃分子不 断地被合成报道, 新型大环芳烃设计构建及其功能研究也成为了大环与超分子化学中一个新的重点与热点研究课题. 综述了新型大环芳烃的研究进展，重点介绍过去十余年尤其是近几年发展的新型大环芳烃分子合成及其性能. 希望该 综述能够有助于大环芳烃相关的研究工作, 并促进大环芳烃化学的发展.
\end{abstract}

关键词大环芳烃; 合成; 主客体化学; 自组装; 超分子化学

\section{Recent Advances in Novel Macrocyclic Arenes}

\author{
Li, Jing ${ }^{a, b}$ Han, Ying ${ }^{a}$ Chen, Chuanfeng*,a,b \\ ( ${ }^{a}$ CAS Key Laboratory of Molecular Recognition and Function, Institute of Chemistry, \\ Chinese Academy of Sciences, Beijing 100190) \\ ( ${ }^{b}$ University of Chinese Academy of Sciences, Beijing 100049)
}

\begin{abstract}
Calixarenes, pillararenes and their analogues are composed of hydroxy- or alkoxy-substituted aromatic rings bridged by methylene or methenyl groups, which can be collectively called as macrocyclic arenes. Macrocyclic arenes have attracted much attention and increasing interests because of their unique structures, easily synthesis and derivatization, electron-rich cavities and wide applications in supramolecular chemistry, and they have also become one of the most significant and studied synthetic macrocyclic hosts during the last decades. Recently, with the rapid development of macrocycles and supramolecular chemistry, various types of novel macrocyclic arenes except the classic macrocyclic arenes such as calixarenes and pillararenes have been reported. The construction and functionalization of novel macrocyclic arenes have become the new focus and hot topic of macrocyclic and supramolecular chemistry. The recent advances in the synthesis and properties of novel macrocyclic arenes are summarized. It is expected that this review will be helpful to the research of macrocyclic arenes and promote the development of macrocyclic arene chemistry.
\end{abstract}

Keywords macrocyclic arene; synthesis; host-guest chemistry; self-assembly; supramolecular chemistry

自 20 世纪 70 年代底以来, 杯芳烃 ${ }^{[1-3]}$ 由于其特殊结 构、易于合成与衍生化以及在超分子化学等领域中广泛 的应用, 而成为了最重要与研究最多的合成大环主体分 子之一，杯芳烃也因此被誉为继冠醚、环糊精之后的“第 三代大环主体分子”. 2008 年, Ogoshi 等 ${ }^{[4]}$ 报道了首例柱 芳烃, 此后, 这个能够被方便地合成与衍生化以及具有 特殊棱柱状结构与富电子空腔的大环分子引起了人们
越来越多的关注与兴趣 ${ }^{[5]}$, 在分子识别与组装、生物医 药以及材料科学等领域中显示出广泛的应用前景. 杯芳 烃、柱芳烃及其类似物大环分子由于均由烷氧基或羟基 取代的芳环通过亚甲基或次甲基桥连而形成，故而可统 称为大环芳烃 (macrocyclic arenes) ${ }^{[6]}$. 近年来, 随着大环 与超分子化学的快速发展, 除杯芳烃和柱芳烃等经典大 环芳烃之外，各种不同类型、具有新颖结构的大环芳烃

\footnotetext{
* Corresponding author. E-mail: cchen@iccas.ac.cn

Received May 4, 2020; revised May 23, 2020; published online May 29, 2020

Dedicated to the 40th anniversary of Chinese Journal of Organic Chemistry.

Project supported by the National Natural Science Foundation of China (Nos. 91856117, 21332008).

国家自然科学基金(Nos. 91856117, 21332008)资助项目.
} 
分子不断地被合成报道, 新型大环芳烃的设计构建及其 功能与应用研究也成为了大环与超分子化学中一个新 的重点与热点研究课题.

本文将综述在过去十余年、尤其是近年来人们发展 的新型大环芳烃分子(图 1), 重点介绍它们的合成方法, 并概述其结构特点以及功能与应用. 内容主要包括基于
苯环基元的大环芳烃、基于三蝶烯基元的大环芳烃、基 于联苯基元的大环芳烃、基于咔唑基元的大环芳烃、基 于䒺环基元的大环芳烃以及基于蒽环基元的大环芳烃. 希望本综述能够有助于大环芳烃相关的研究工作, 并促 进大环芳烃化学的发展.

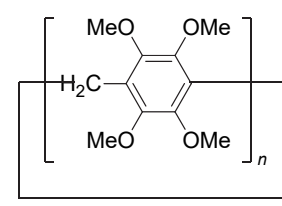

Asar[n]arenes<smiles>COc1cc(Cc2cc(OC)c(OC)cc2O)c(O)cc1Cc1cc(OC)c(Cc2cc(OC)c(Cc3cc(O)c(O)cc3O)cc2O)cc1O</smiles>

Hybrid[ $n]$ arenes

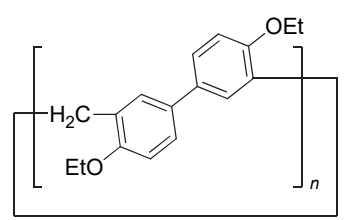

Biphen[n]arenes

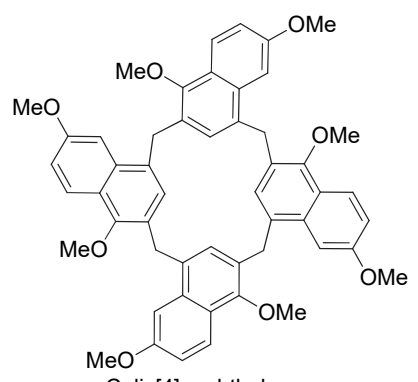

Calix[4]naphthalenes

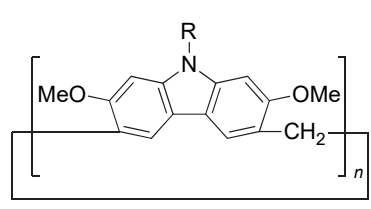

Calix[n]carbazoles

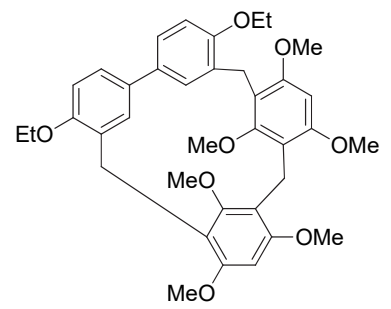

Hybrid[3]arene

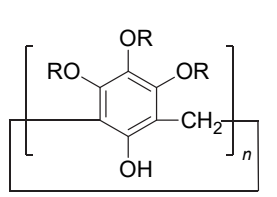

Calix $[n]$ tetrolarenes

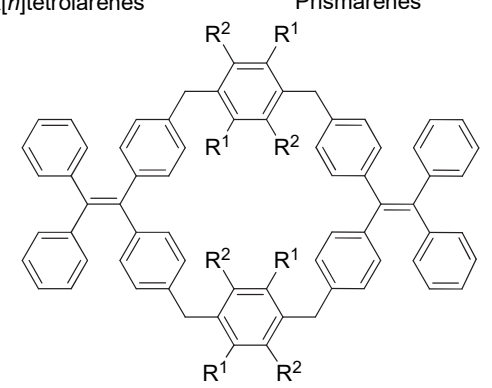

Tetraphenylethylene pillar[6]arenes

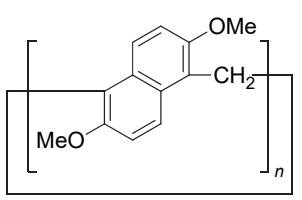

Prismarenes $\mathrm{R}^{2} \quad \mathrm{R}^{1}$

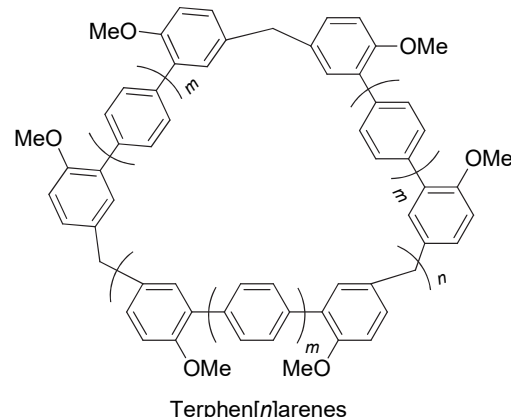

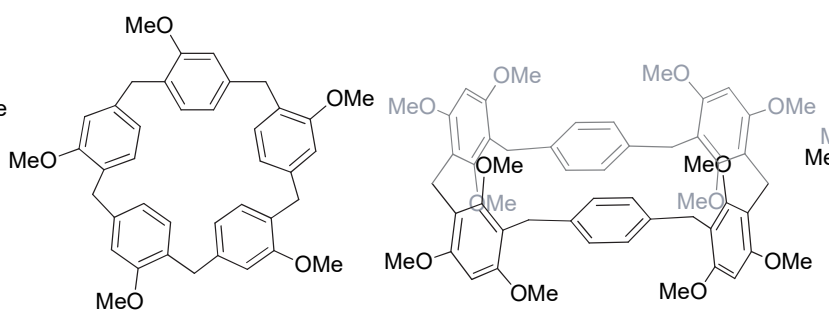

Geminiarene

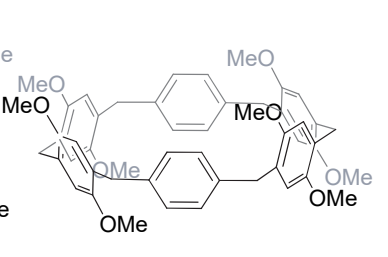

Leaning pillar[6]arene

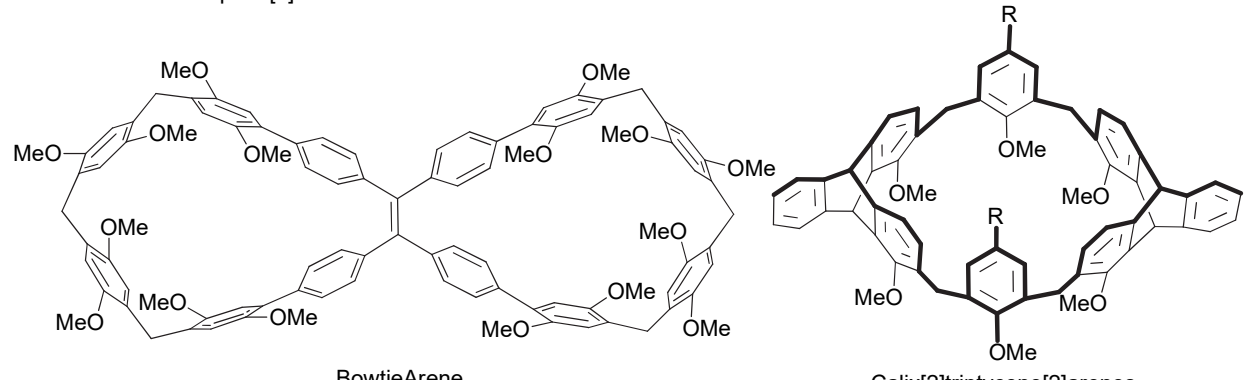

Calix[2]triptycene[2]arenes

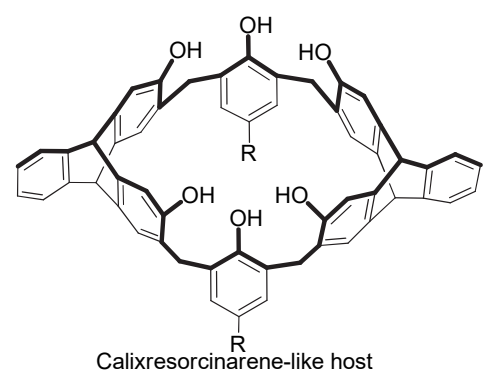

Calixresorcinarene-like host

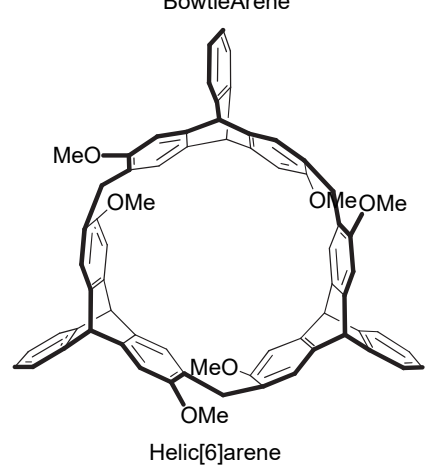

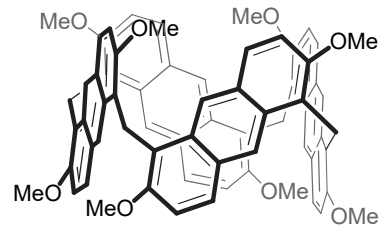

Pagoda[4]arene

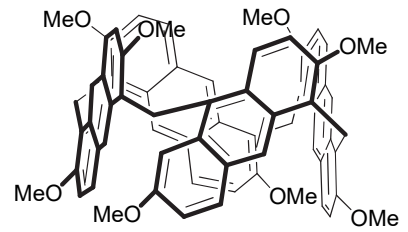

i-Pagoda[4]arene

图 1 新型大环芳烃的结构

Figure 1 Structures of novel macrocyclic arenes 


\section{1 基于苯环基元的大环芳烃}

\section{1 姜芳烃}

2013 年, Stoddart 课题组 ${ }^{[7]}$ 报道了一种新的大环芳 烃, 由于前体 $1,2,4,5$-四甲氧基苯(1)被称为姜甲醚, 因 此将其命名为姜芳烃(Asararenes). 由 1 出发, 通过其与 甲醛在三氟化硼乙醚催化下缩合反应, 发现在 $80{ }^{\circ} \mathrm{C}$ 下 能够以 $14 \%$ 产率主要生成热力学控制的环 [6]聚体产物; 当反应在低温下进行时, 则可同时分离得到七种环聚
体，即姜[6]～姜[12]芳烃 $($ Scheme 1)，姜[13]～姜[15]芳 烃只能通过质谱检测。通过核磁及单晶结构表征了姜芳 烃大环的结构. 类似于柱芳烃, 姜芳烃在分子识别与组 装方面也具有潜在用途.

\section{2 拓展柱 $[n]$ 芳烃}

郑炎松等 ${ }^{[8]}$ 将柱芳烃与四苯乙烯结合，合成得到了 四苯乙烯柱[6]芳烃(Tetraphenylethylene pillar[6]arenes, Scheme 2,a). 该大环在固态下可对三硝基甲苯进行快

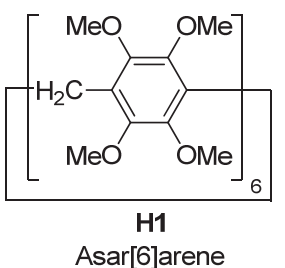

Asar[6]arene

\section{$\mathrm{HCHO} / \mathrm{BF}_{3} \cdot \mathrm{OEt}_{2}$
$\mathrm{DCE} / 80{ }^{\circ} \mathrm{C} / 2 \mathrm{~h}$} product
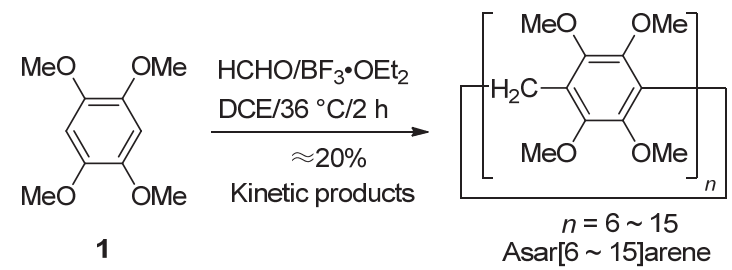

图式 1 姜芳烃的合成

Scheme 1 Synthesis of asararenes

(a)
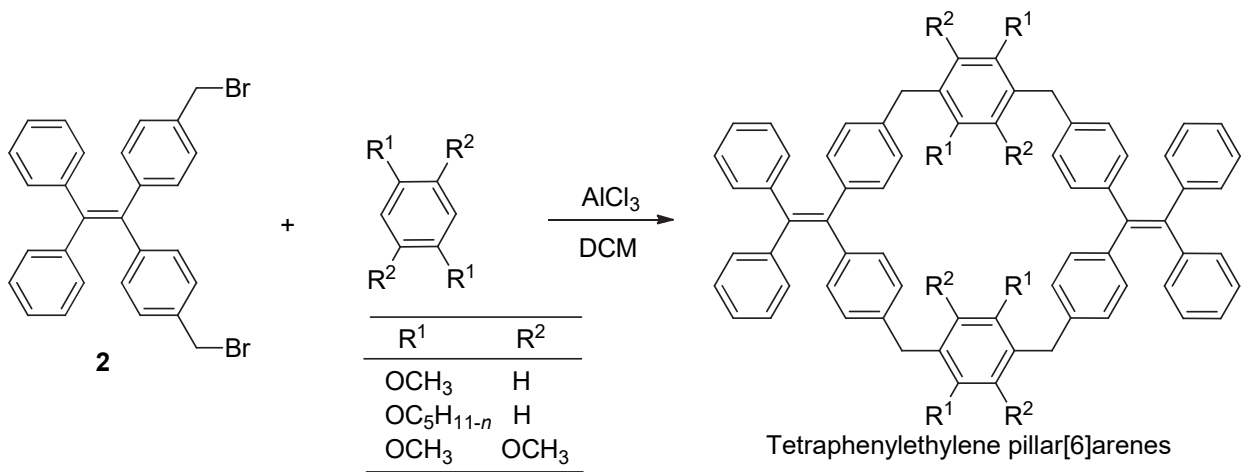

$\mathrm{H} 2 \mathrm{a}$

(b)<smiles>CCOc1cc(Cc2cc(OCC)c(Cc3cc(OCC)c(Cc4cc(OCC)c(OCC)cc4OCC)cc3OCC)cc2OCC)c(OCC)cc1Cc1cc(OCC)c(Cc2cc(OCC)c(Cc3cc(OCC)c(OCC)cc3OCC)cc2OCC)cc1OCC</smiles><smiles>CC[C+]1CCCCC1</smiles>

(1) $n$-BuLi, THF

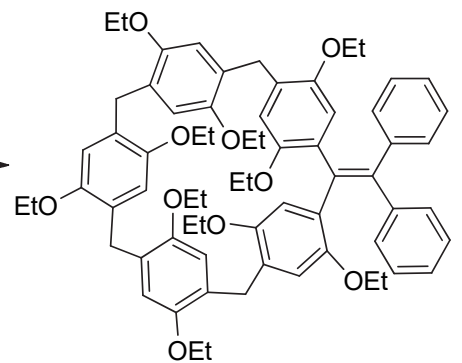

(c)<smiles>COc1ccc(OC)cc1</smiles><smiles>CCOC(OC)(OC)OCCOC</smiles>
Tetraphenylethylene pillar[5]arene $\mathrm{H} 2 \mathrm{~b}$

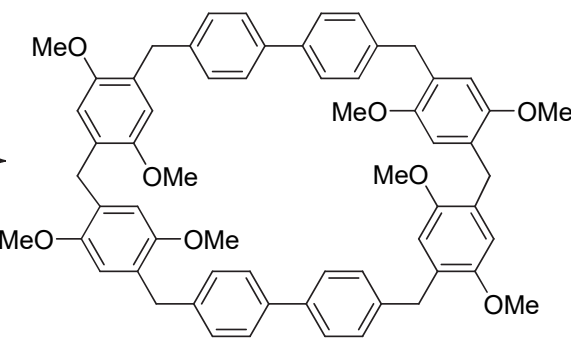

Biphenyl-extended pillararene $\mathrm{H} 2 \mathrm{C}$

图式 2 拓展柱 $[n]$ 芳烃的合成

Scheme 2 Synthesis of extended pillar $[n]$ arenes 
速检测, 检测限为 $10^{-12} \mathrm{~mol} / \mathrm{L}$. 同时其溶液也可用于快 速检测空气中的三硝基甲苯分子. 最近, 姜建壮等 ${ }^{[9]}$ 将 乙氧基柱[5]芳烃中单个桥连亚甲基锂化后与二苯甲酮 发生亲核加成反应, 经脱水后得到四苯乙烯柱 [5]芳烃 (Tetraphenylethylene pillar[5]arene, Scheme 2, b). 该大环 在溶液中及固态下均与已二腈形成稳定的 $1: 1$ 络合物. 由于该主客体单晶结构中四苯乙烯的两个外围苯环近 乎垂直, 使其在固态下不具有聚集诱导发光特性.

2016 年, 杨英威等 ${ }^{[10]}$ 通过片段缩合法以 $50 \%$ 产率 得到[2]联苯拓展柱 [6]芳烃 H2c (Scheme 2, c). 单晶结构 表明 $\mathbf{H} 2 \mathrm{c}$ 呈拉伸的六边形. 通过分析 H2c 包结甲苯与间 二甲苯的晶体结构, 作者推测邻二甲苯及对二甲苯由于 位阻效应不能进入大环空腔, 因此, 该大环有望用于二 甲苯混合物的分离. 此外, 该课题组 ${ }^{[11]}$ 从 $\mathbf{H} \mathbf{c}$ 出发得到 水溶性联苯拓展柱[6]芳烃. 苂光测试表明该水溶性大 环对菜磺酸盐客体络合能力较强, 络合常数可达 $10^{6}$ $\mathrm{L} / \mathrm{mol}$. 向该大环水溶液中加入 2 equiv.的 2,6-菜二磺酸 钠盐, 溶液中立刻析出主客体复合物, 表明该大环可望 用于水相中萘磺酸盐检测及分离. 通过将 $\mathbf{H 2 c}$ 后修饰后 与含四苯乙烯的铵盐客体掺杂可得到苂光性质的超分 子聚合物 ${ }^{[12]}$. 该超分子聚合物可实现水相中采离子的
识别与萃取, 用 $\mathrm{Na}_{2} \mathrm{~S}$ 处理后可循环利用.

\section{3 杂芳烃}

通过间二甲氧基苯 3 和对二烷氧基苯 $\mathbf{4}$ 与多聚甲醛 在布朗斯特酸催化下反应, Szumna 等 ${ }^{[13]}$ 以 $26 \% \sim 53 \%$ 的 总产率得到一系列杂 $[n]$ 芳烃 (Hybrid $[n]$ arenes, Scheme $3)$. 根据组成基元的不同可分为 $[2+2] 、[3+1]$ 及 $[3+2]$ 杂芳烃. 此外, 作者还发现将雷琐酚大环和柱[5]芳烃混 合物在布朗斯特酸催化下反应，同样能够得到相应的杂 芳烃. 研究表明在酸催化下该环化反应具有可逆性，环 化反应进行的程度取决于目标大环的稳定性, 是一个热 力学控制的过程. 核磁共振氢谱研究结果显示多数杂芳 烃具有柔性与不固定的构象结构, 杂[4]芳烃 H3a 和 H3b 由于部分芳香环的旋转受阻, 因而使其具有一定的 刚性，表现为一对非对映异构体. 杂[4]芳烃 H3c 为一对 对映异构体，但作者只得到其消旋体.

2016 年, 喻国灿等 ${ }^{[14]}$ 从杂 $[4]$ 芳烃 H3d 出发, 合成 得到一种阴离子型的水溶性杂[4]芳烃 WH3d (Scheme 4), 测试了其在水中对百草枯的络合性质, 络合常数可 达 $10^{4} \mathrm{~L} / \mathrm{mol}$ ，并且该络合过程可通过酸碱进行调控.
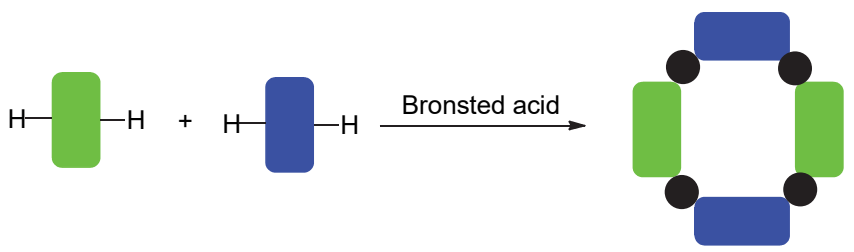

Bronsted acid

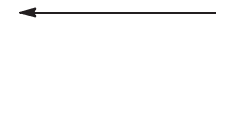

H3

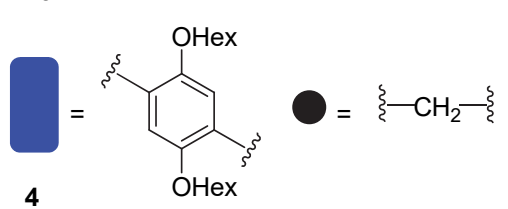<smiles>CCCCc1cc(OC)c(CC)cc1OC</smiles>

3

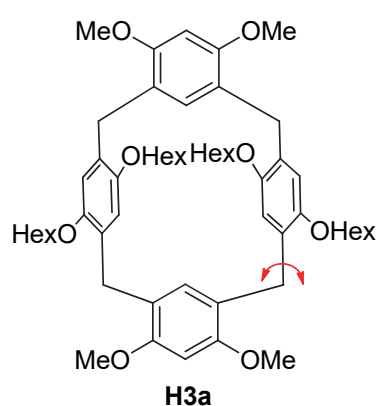

H3a
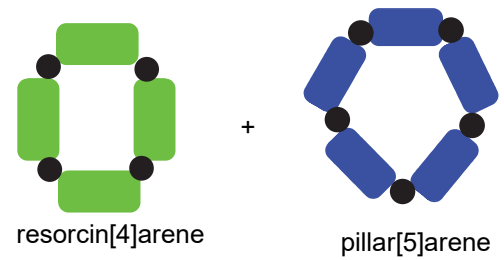

pillar[5]arene

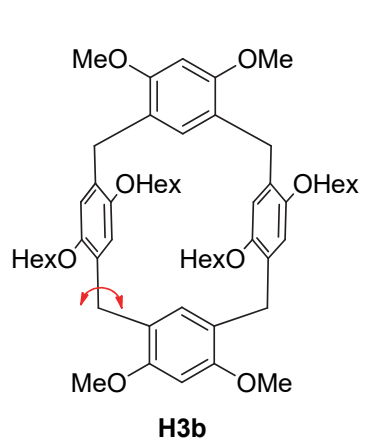

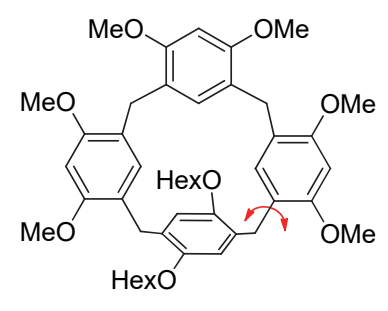

H3c $(M)$

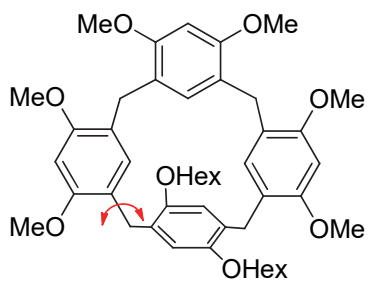

H3c $(P)$

\footnotetext{
$\curvearrowleft$ inhibited rotation
}

图式 3 杂 $[n]$ 芳烃的合成及结构式

Scheme 3 Synthesis and structures of hybrid $[n]$ arenes 

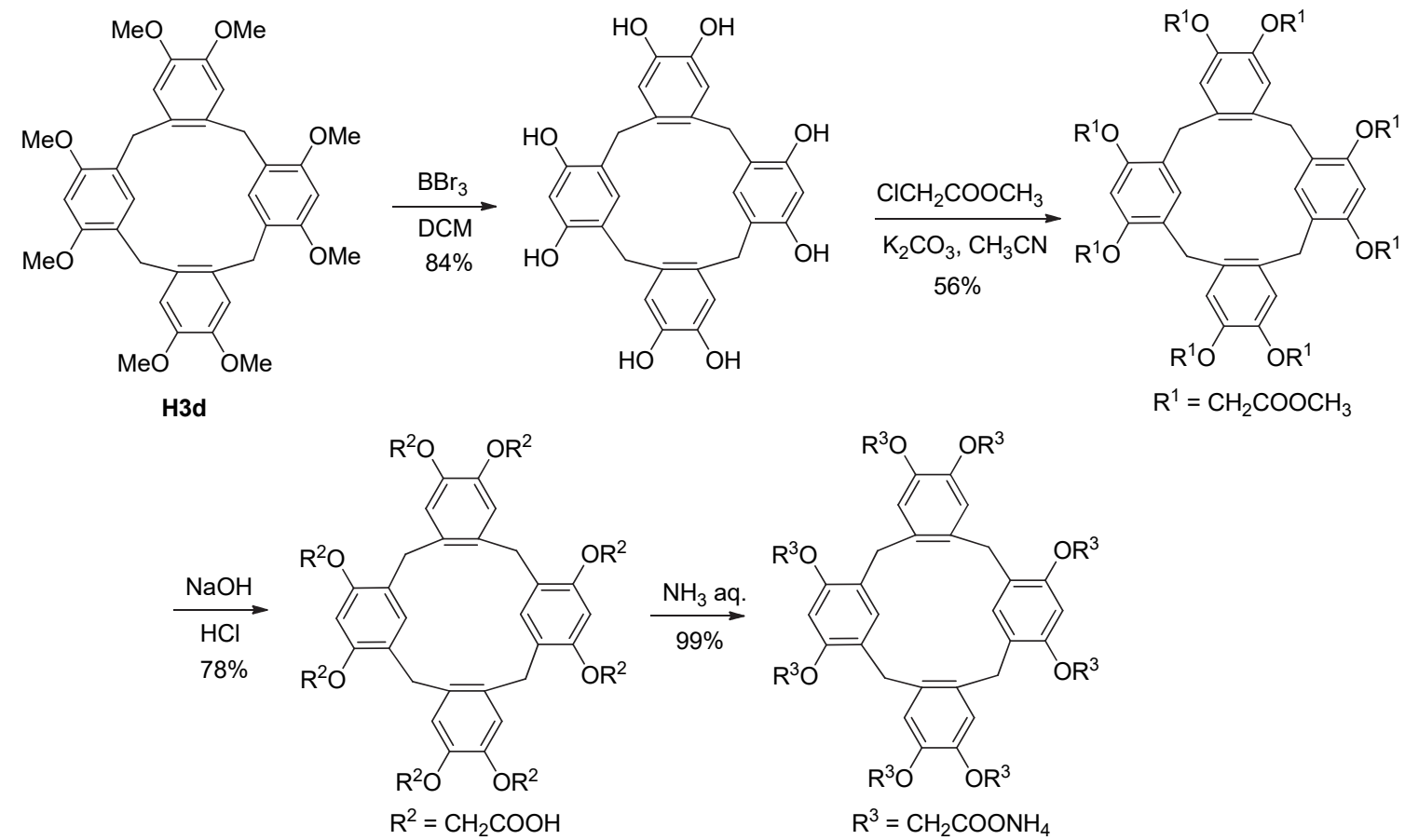

$\mathrm{R}^{2}=\mathrm{CH}_{2} \mathrm{COOH}$

WH3d

图式 4 水溶杂[4]芳烃的合成

Scheme 4 Synthesis of water-soluble hybrid[4]arene

\section{4 杯 $[n]$ 四酚芳烃}

从 5 出发, 在三氟乙酸催化下与多聚甲醀缩合, 能 够以 $73 \%$ 的总产率得到环四聚体与环五聚体. Cohen 和 Zafrani ${ }^{[15]}$ 命名其为杯 $[n]$ 四酚芳烃 (Calix $[n]$ tetrolarene, Scheme 5). 通过核磁及单晶结构研究发现, 该大环上沿 具有类似连苯三酚杯芳烃的结构, 下沿具有类似杯芳烃 的结构, 故而可以看作两种大环的结合体. 杯芳烃及联 苯三酚杯芳烃均较难得到环五聚体, 而杯 [5]四酚芳烃 则可以以 $43 \%$ 的核磁产率得到.

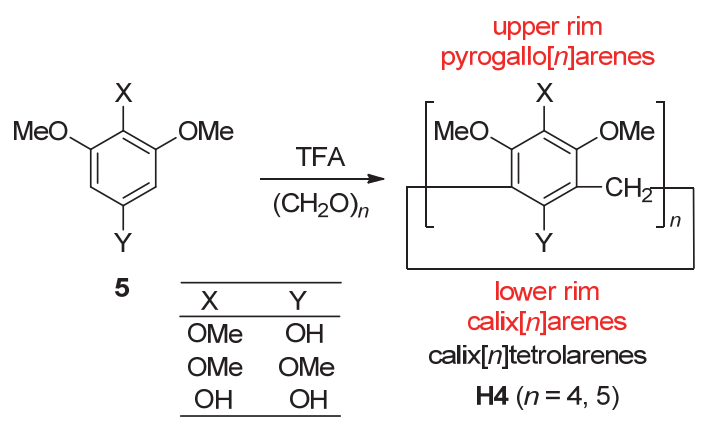

图式 5 杯 $[n]$ 四酚芳烃的合成

Scheme 5 Synthesis of calix $[n]$ tetrolarenes

\section{5 斜柱[6]芳烃}

2018 年, 杨英威等 ${ }^{[16]}$ 通过两步反应以 $36 \%$ 产率得 到一个柱芳烃类似物, 并称之为斜柱[6]芳烃(Leaning
Pillar[6]arene, Scheme 6). 密度泛函理论(DFT)计算结果 表明斜柱 [6]芳烃 H5b 的转动能垒低于柱[6]芳烃. 此外 静电势能计算显示斜柱[6]芳烃苯环上电荷密度分布不 均, 两端由于氢键作用产生极化效应, 从而影响其主客 体识别行为. 值得注意的是, 通过将 H5a 直接氧化即可 得到对应的醌化合物 H5c.

该课题组 ${ }^{[17]}$ 从 $\mathrm{H5}$ 出发, 通过后修饰得到了阴离子 型水溶性斜柱 [6]芳烃. 将该水溶性大环作为还原剂和 稳定剂，可一步得到其修饰的金纳米粒子. 该纳米粒子 可用作甲基联吡啶盐的检测剂，检测限可达 $10^{-8} \mathrm{~mol} / \mathrm{L}$. 此外，该纳米粒子还可高效催化对硝基苯酚的还原氢化 反应，表观速率常数达 $0.156 \mathrm{~min}^{-1}$. 通过将斜柱 [6]芳烃 与四苯乙烯等其它材料掺杂, 该课题组进一步构筑了踠 豆状的具有双重刺激响应性的有机一无机杂化超分子体 系 ${ }^{[18]}$. 最近，他们 ${ }^{[19]}$ 将乙氧基斜柱 [6]芳烃作为固体吸 附材料，用于卤代烃异构体的吸附与分离. 例如: 将 1溴丁烷及 1-溴戊烷从其与 2-溴丁烷及 2-溴戊烷的混合 物中分离，分离效率高达 $96.3 \%$ 。单晶衍射、粉末衍射 及热重分析表明选择性源于主客体络合模式及稳定性 的差异. 基于三联吡啶衍生化的斜柱[6]芳烃，杨英威 等 ${ }^{[20]}$ 利用主客体相互作用及金属配体配位作用正交自 组装，还构建了一种具有多重响应性的荧光超分子聚合 物. 该超分子聚合物经受酸、竞争性主体或者是加热等 外界刺激能够发生解离, 并实现从凝胶到溶胶的转变. 


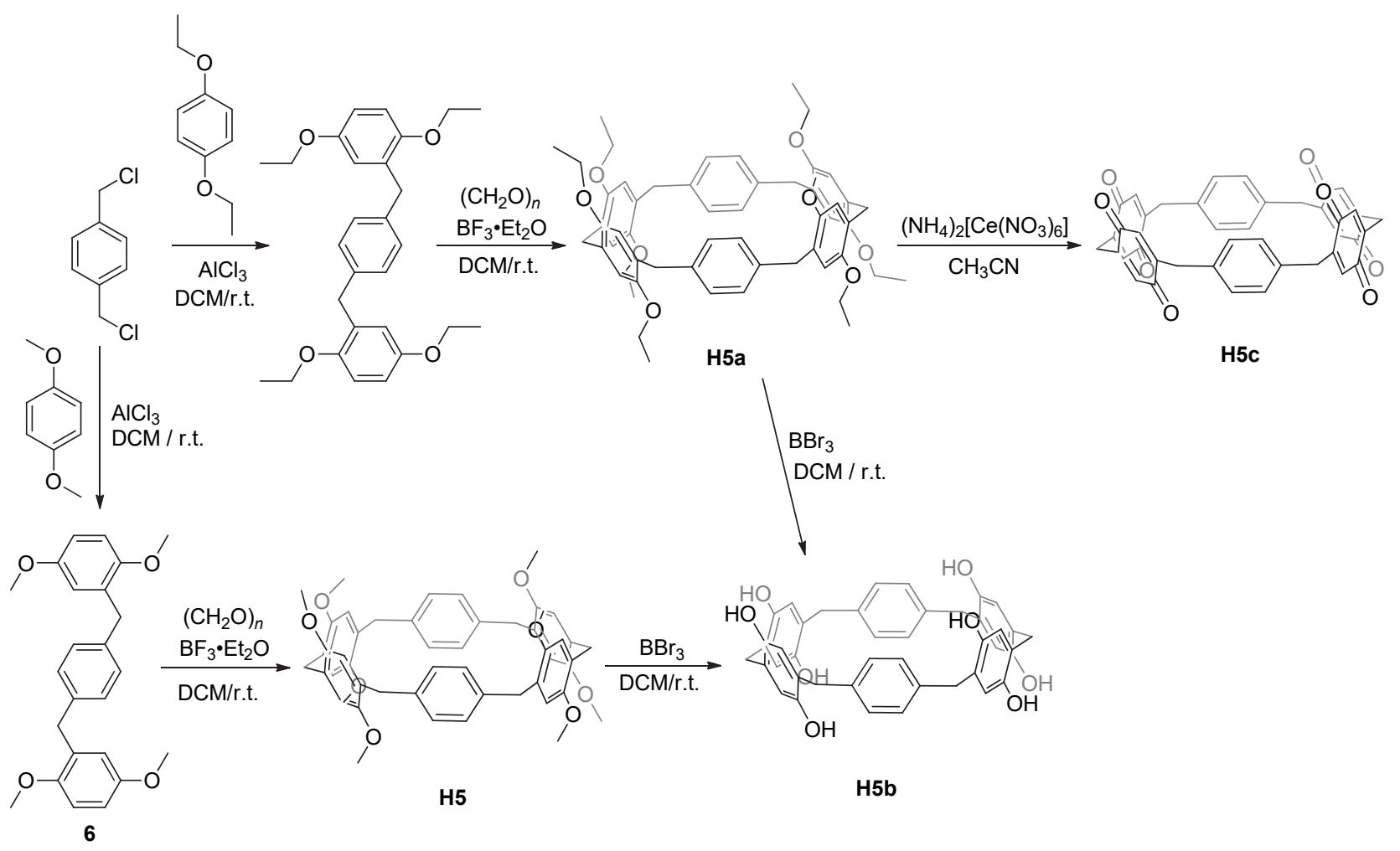

图式 6 斜柱[6]芳烃的合成

Scheme 6 Synthesis of leaning pillar[6]arene

\section{6 双子芳烃}

通过将对二甲氧基苯替换为间三甲氧基苯，杨英威 等 ${ }^{[21]}$ 利用与斜柱 [6]芳烃相同的合成手法得到一个新的 柱芳烃类似物, 称之为双子芳烃 (Geminiarene, Scheme 7). 双子芳烃 $\mathrm{H6}$ 的命名源于其两种可相互转化的固态 结构. 主客体性质研究表明 $\mathrm{H} 6$ 可与氯代环已烷形成 $1: 4$ 的络合物, 这有别于传统的 $1: 1$ 或者 $1: 2$ 的络合 物. $\mathrm{H6}$ 固态下有两种晶型: $\mathrm{H} 6 \alpha$ 和 $\mathrm{H} 6 \beta$. H6 $\alpha$ 可在固-液 条件下选择性包结且分离氯代环已烷, 分离纯度可达

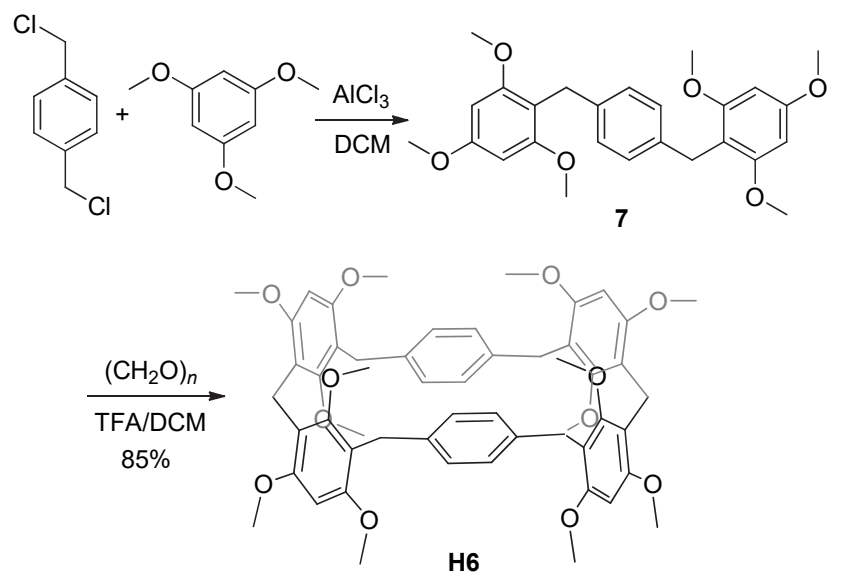

图式 7 双子芳烃的合成

Scheme 7 Synthesis of geminiarene
$97 \% . \mathrm{H} 6 \beta$ 可在固一气条件下选择性包结且分离氯苯, 分 离纯度可达 $88 \%$. 研究发现 $\mathrm{H6} \alpha$ 是热力学稳定产物, 故 而利用此特性, 可通过分馏方法一次性的将氯苯及氯代 环己烷分别以 $87 \%$ 及 $97 \%$ 的纯度从其相应的 1:1 混合 体系中分离.

\section{7 领结芳烃}

最近, 从欢课题组 ${ }^{[22]}$ 将四苯乙烯与柱芳烃相结合, 通过片段缩合方法有效地得到了具有双空腔结构的领 结芳烃(Bowtiearene, Scheme 8). 该大环分子展现出多 重刺激响应的苂光特性, 液态及固态下均可通过改变条 件实现蓝光到黄光的转变. 作者还进一步研究了领结芳 烃的力致/气致变色性质, 发现对晶态的蓝光固体材料 施加外力后该材料转为黄光, 之后将其置于二甲苯气体 氛围中则可重新发出蓝光. 光学性质转变的原因可归结 于外界刺激导致晶态材料晶型的转变.

\section{8 头冠[5]芳烃}

2020 年, Sue 和 Zuilhof 等 ${ }^{[23]}$ 报道一种新的大环芳 烃, 头冠[5]芳烃(Tiara[5]arene, Scheme 9). 此大环无法 通过甲氧基苯与多聚甲醛缩合得到, 而是先得到两端官 能团不同的柱[5]芳烃衍生物 9, 之后选择性地将一端官 能团脱除, 从而得到外形类似皇冠的头冠 [5]芳烃 $\mathbf{H 8}$. 在三溴化硼作用下可定量地得到全部脱除甲基的 H8a. 晶态的 $\mathbf{H 8}$ 可将苯从其与环已烷体积比为 $1: 1$ 的混合液 


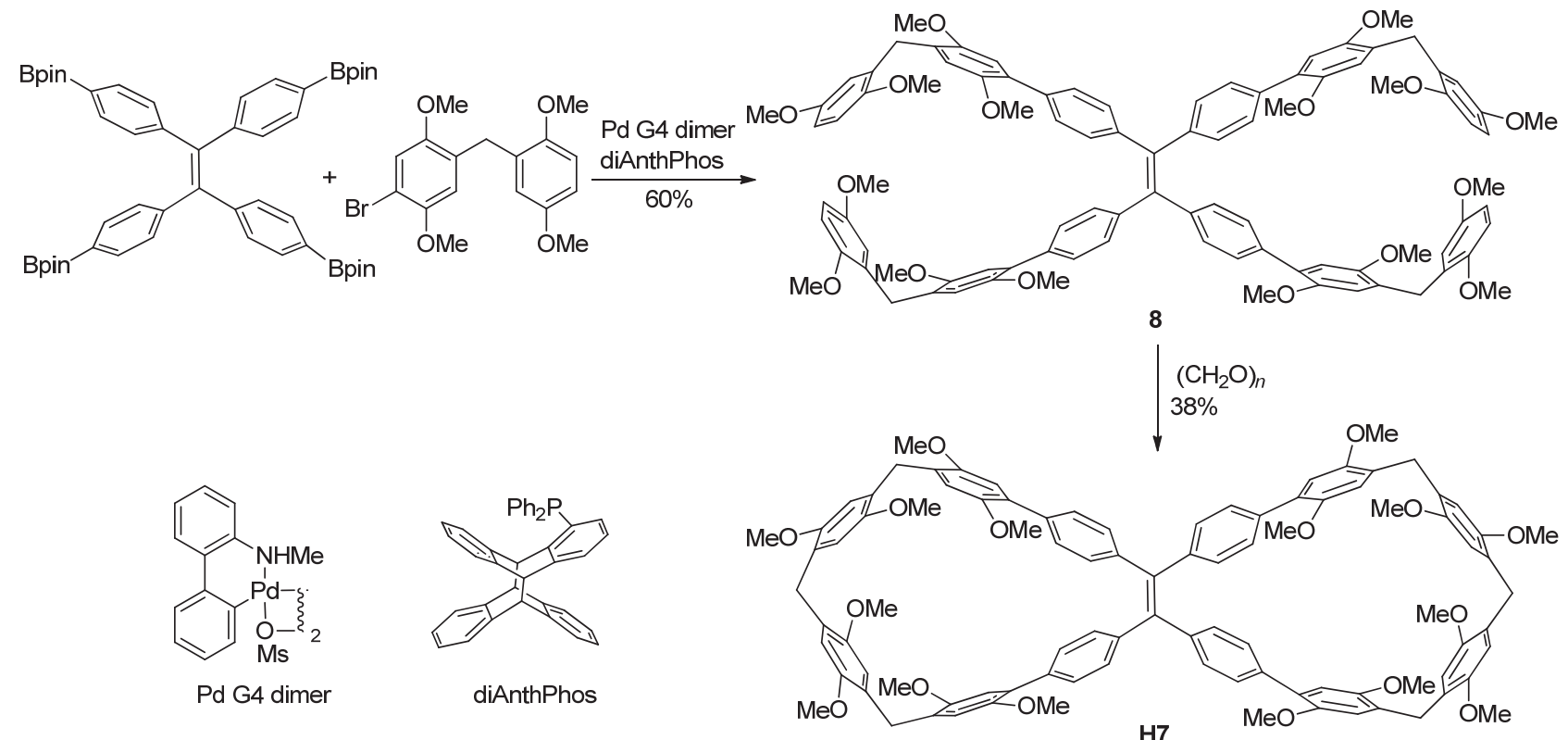

图式 8 领结芳烃的合成

Scheme 8 Synthesis of bowtiearene
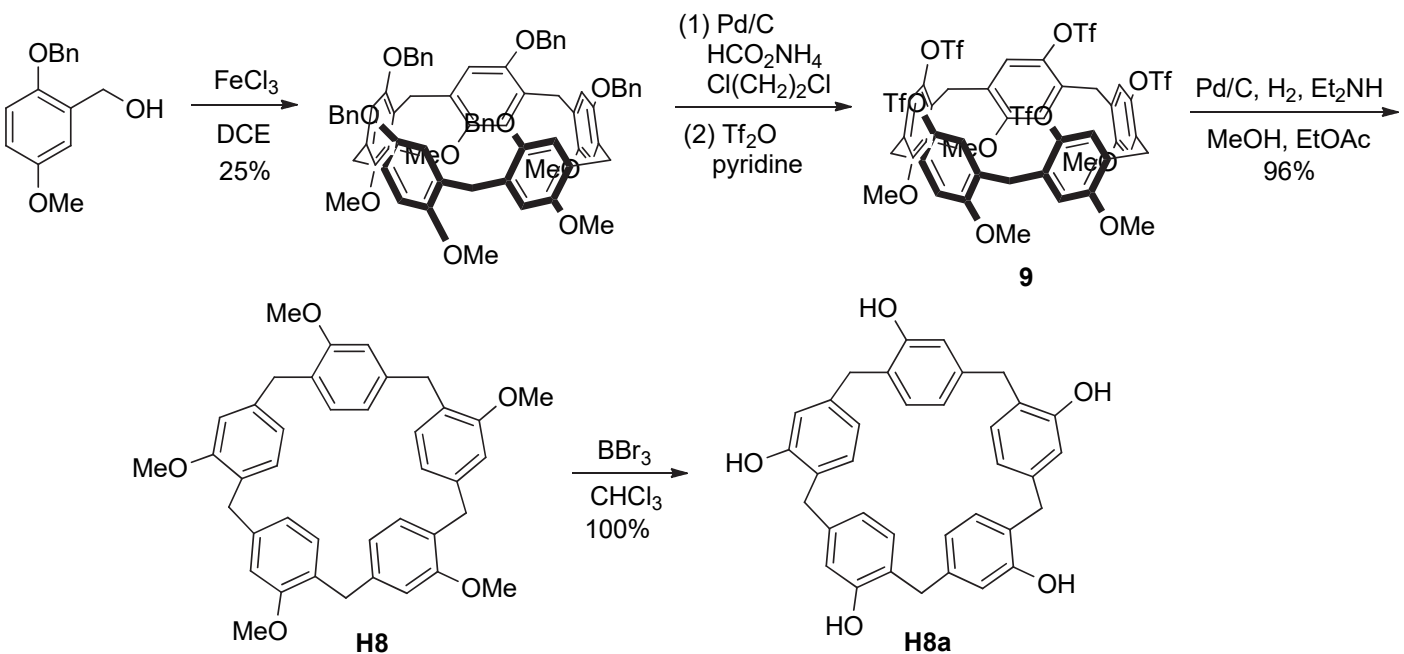

图式 9 头冠 [5]芳烃的合成

Scheme 9 Synthesis of tiara[5]arene

中分离, 分离效率高达 $92.3 \%$.

\section{2 基于三蝶烯基元的大环芳烃}

\section{1 杯[2]三蝶烯[2]芳烃}

三蝶烯 ${ }^{[24-25]}$ 具有独特的刚性结构, 已在超分子化学 与材料化学等领域中得到了广泛的应用. 基于三蝶烯结 构基元, 我们课题组 ${ }^{[26-27]}$ 由 $\mathbf{1 0}$ 与 $\mathbf{1 1}$ 出发, 分别通过一锅 煮或片段偶联方法得到两种杯 [2] 三蝶烯 [2] 芳烃 (Calix[2]triptycene[2]arenes, Scheme 10, a), 产率为 17\% $25 \%$. 大环芳烃 H9a 与 H9b 互为非对应异构体, 其中 H9a 为顺式异构体, H9b 为反式异构体. 变温 NMR 结果
显示 $\mathrm{H9a}$ 和 $\mathrm{H9b}$ 在溶液中均具有构象固定的特性. 与传 统的杯 [6]芳烃相比, H9a 和 H9b 在无需引入辅助基团的 情况下能够与联吡定盐等客体形成稳定的络合物. 当 $\mathrm{R}$ 为苯基时，顺式或反式异构体大环芳烃还能够与 $\mathrm{C}_{60}$ 及 $\mathrm{C}_{70}$ 形成 $1: 1$ 的络合物, 络合常数均大于 $10^{4} \mathrm{~L} / \mathrm{mol}$.

按照上述类似合成方法，通过 $\mathbf{1 0}$ 与 1,3 -二甲氧基或 1,3-二羟基取代苯衍生物 $\mathbf{1 3}$ 缩合反应，得到一系列新的 杯[2] 三蝶烯[2]芳烃类似物 H9a'和 H9b' (Scheme 10, b). $\mathrm{H}^{\prime} \mathrm{a}^{\prime}$ 与 $\mathrm{H}^{\prime} \mathrm{b}^{\prime}$ 在溶液中也都具有构象固定的特性, 并且 能够与 4,4'-联吡啶盐客体在溶液中或固态下形成 $1: 1$ 的稳定络合物. 进一步通过主客体络合物的封端反应, 
(a)
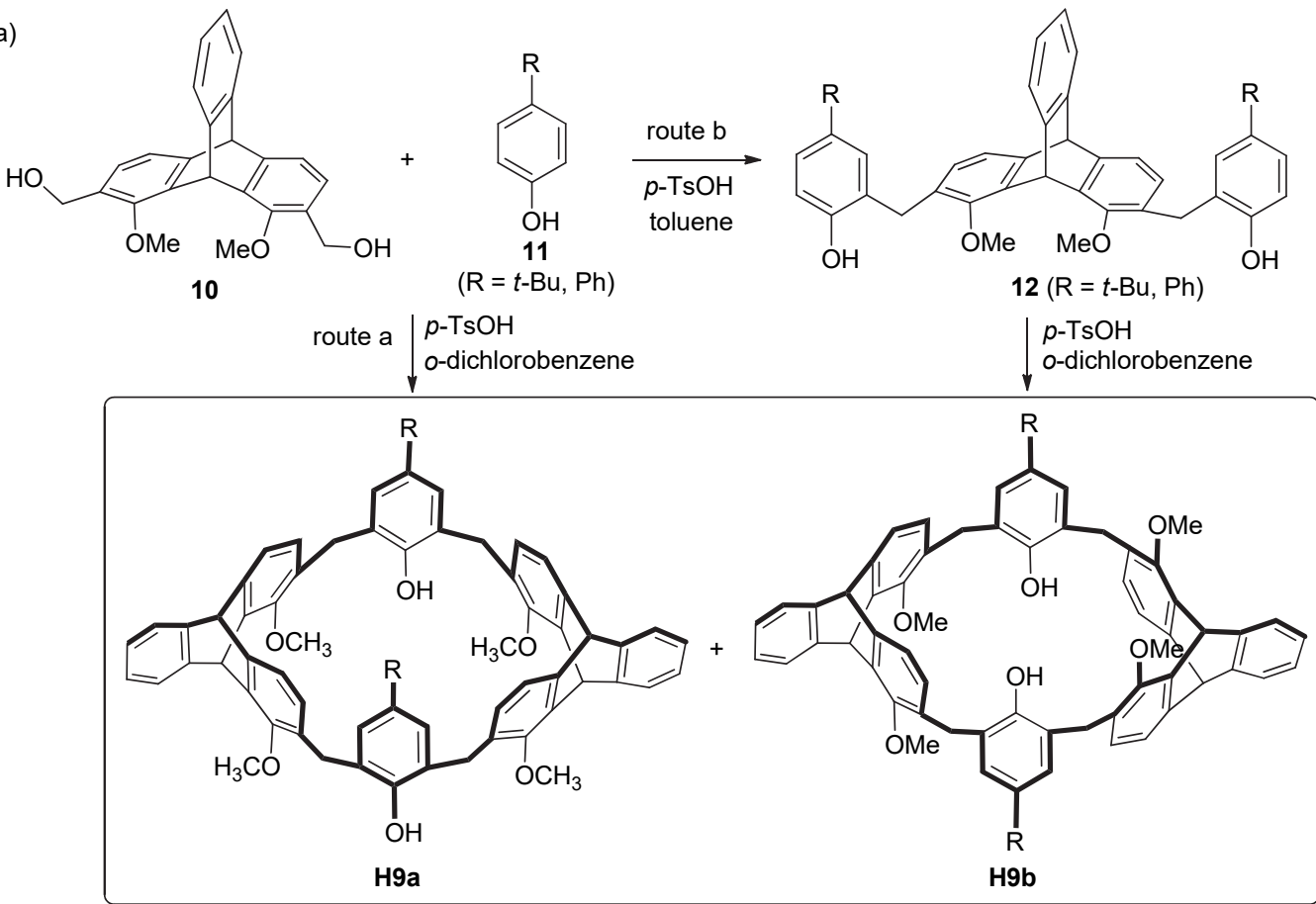

(b)
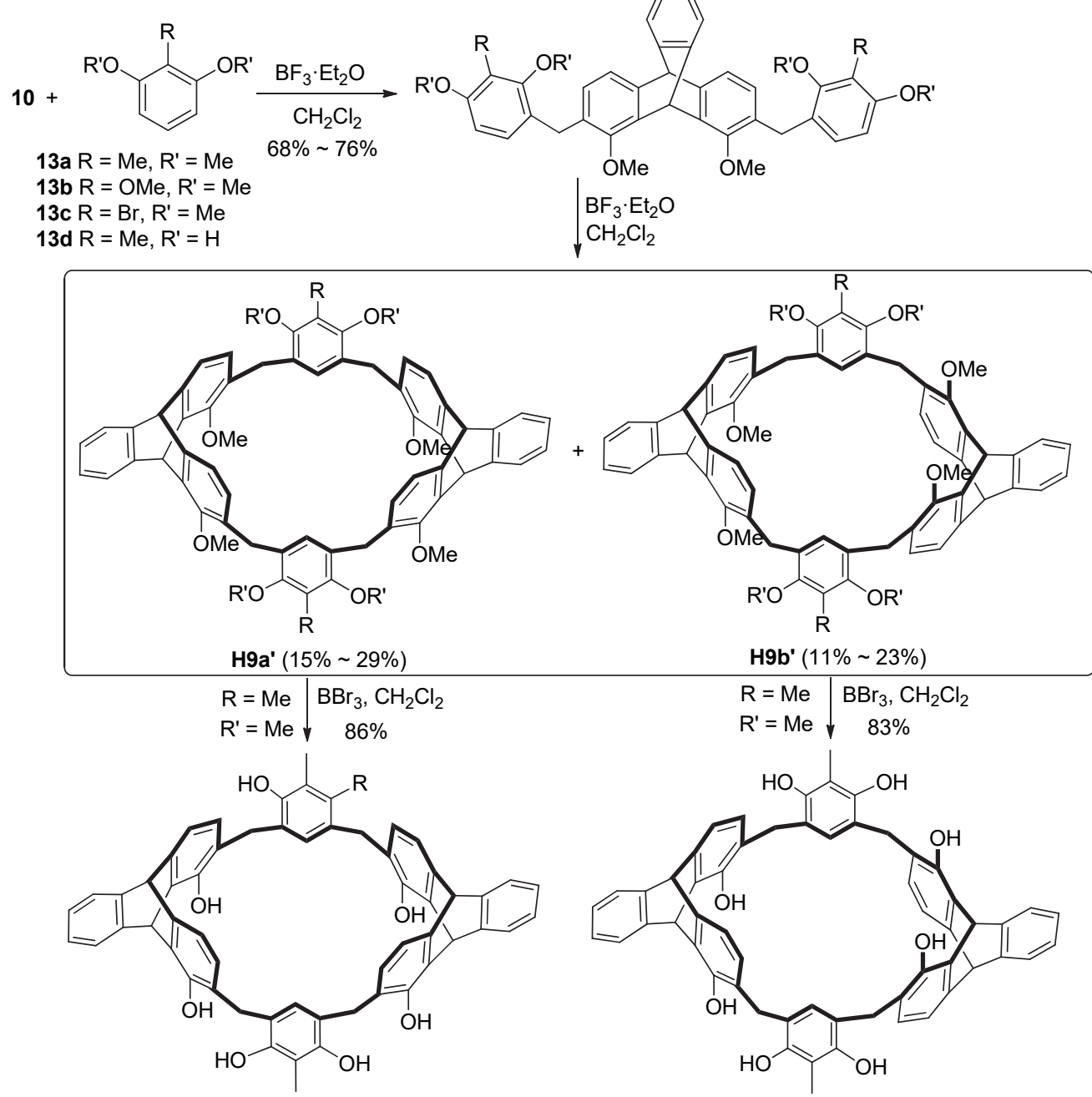

图式 10 杯[2] 三蝶烯[2]芳烃的合成

Scheme 10 Synthesis of calix[2]triptycene[2]arenes 
还得到一个 [2]轮烷超分子组装体 ${ }^{[28]}$.

\section{2 杯[1] 三蝶烯[3]芳烃}

我们 ${ }^{[30-31]}$ 通过 12 与 14 缩合反应得到一系列杯[1] 三蝶烯[3]芳烃 H10 (Calix[1] triptycene[3]arenes, Scheme $11, a)$, 产率为 $21 \% \sim 25 \%$. 由二澳取代的三蝶烯衍生物 15 出发, 能够方便地得到二溴取代杯 [1] 三蝶烯[3]芳烃 H10' (Scheme 11, b). 叔丁基取代的大环芳烃 H10 经液 溴于室温下处理, 高产率地得到五澳取代的杯 [1]三蝶 烯[3]芳烃 H10" (Scheme 11，c). 澳代大环芳烃经过 Suzuki-Miyaura 反应, 得到一系列加深空腔结构的杯 [1] 三蝶烯[3] 芳烃衍生物. H10 及其衍生物都具有固定的构 象, 并且即使在 $100{ }^{\circ} \mathrm{C}$ 下也不发生构象翻转. 在固态下 杯[1] 三蝶烯[3]芳烃能够包结二氯甲烷、甲醇等有机小 分子.

\section{3 类杯雷琐酚大环芳烃}

由三蝶烯衍生物 16 出发, 经过两步反应, 我们 ${ }^{[29]}$ 还方便地以 $20 \% \sim 22 \%$ 的产率得到类杯雷琐酚大环芳烃
H11 (Calixresorcinarene-like host, Scheme 12). 该大环芳 烃为顺式异构体, 变温核磁结果表明三蝶烯基元的引入 能够有效地固定其在溶液中的构象. 单晶结构显示该大 环在固态下能够形成胶囊状的二聚体, 并进一步组装成 为管道结构，管道中包结二氯甲烷分子.

\section{4 螺芳烃}

2016 年，我们 ${ }^{[32]}$ 报道了一种新型大环芳烃，由于该 大环具有类似螺母的手性结构, 因而将其命名为螺芳烃 (Helicarene). 首先由 2,6-二甲氧基葱出发, 通过三步常 规反应合成三蝶烯衍生物 $\mathbf{1 7}$, 然后在对甲苯磺酸催化 下 17 经环化反应以 $15 \%$ 的产率得到环三聚体，最终通 过脱甲基、引入手性辅助基团以及经过高效液相色谱 (HPLC) 手性柱拆分, 得到一对螺芳烃对映异构体 (Scheme 13). 对映异构体的绝对构型通过其前体的单 晶结构确定. 2018 年, 我们 ${ }^{[33]}$ 由光活性的前体分子 17 出 发, 通过三氯化铁催化环化反应，可以克级量地得到相 应手性螺芳烃(Scheme 14), 变温核磁研究表明螺芳烃 在溶液中具有固定的构象. 此外, 螺芳烃能够方便地进

(a)
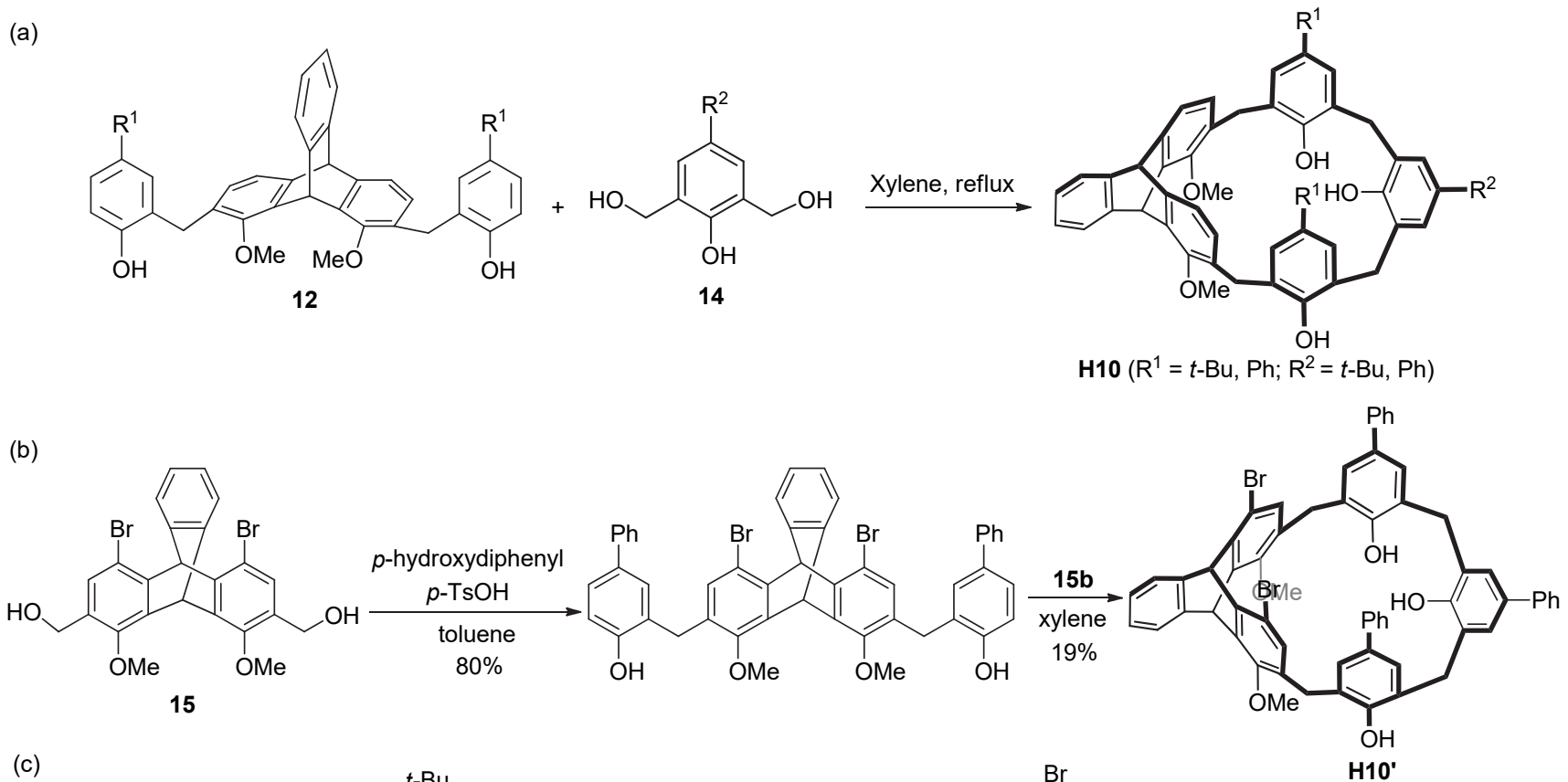

(c)
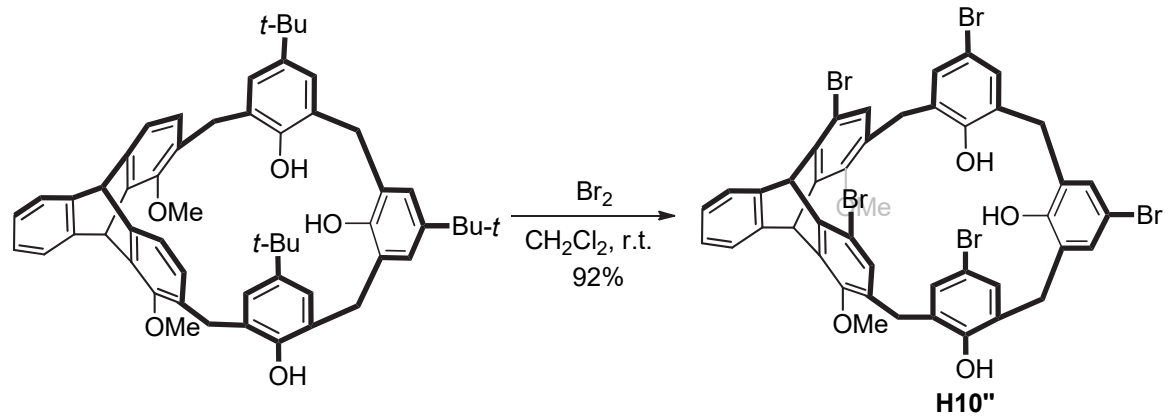

图式 11 杯[1] 三蝶烯[3]芳烃的合成

Scheme 11 Synthesis of calix[1]triptycene[3]arenes 


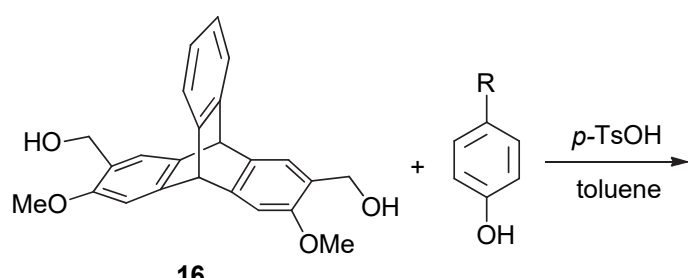

16
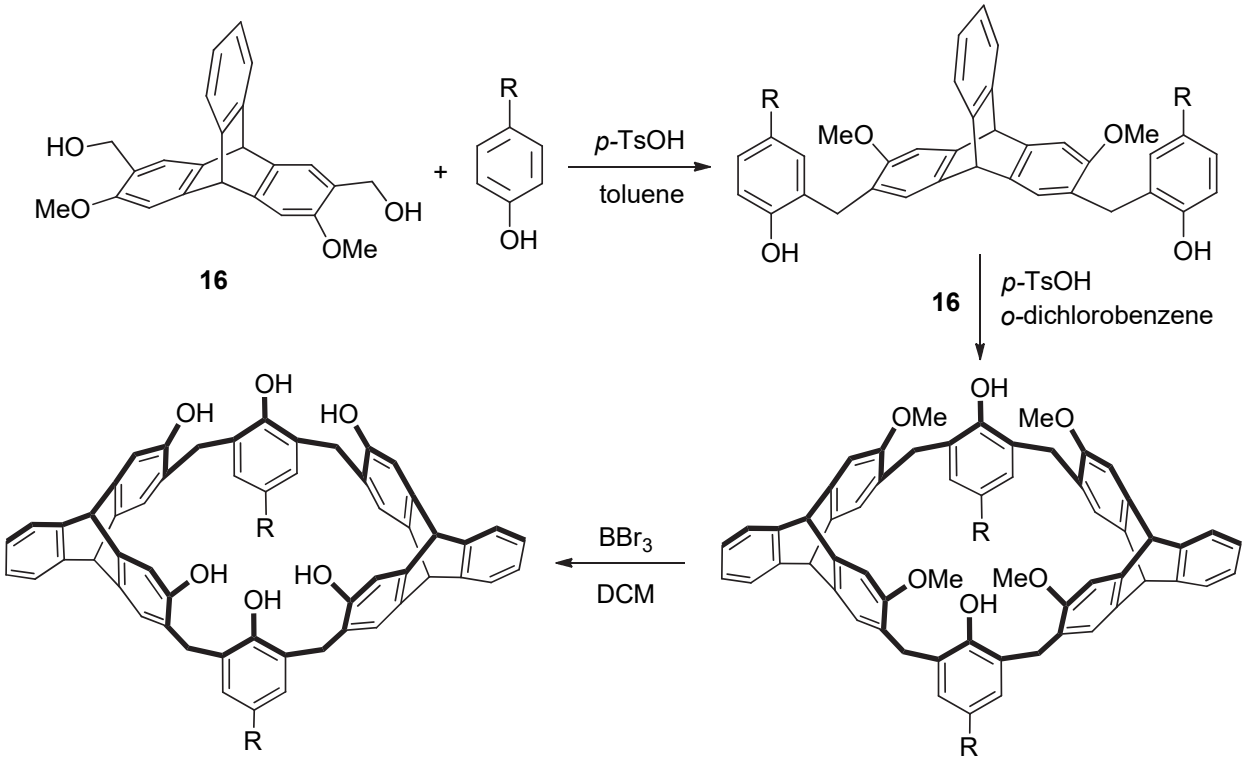

$\mathrm{H} 11(\mathrm{R}=t-\mathrm{Bu}, \mathrm{Ph}, i-\mathrm{Pr})$

图式 12 类杯雷琐酚主体的合成

Scheme 12 Synthesis of calixresorcinarene-like hosts
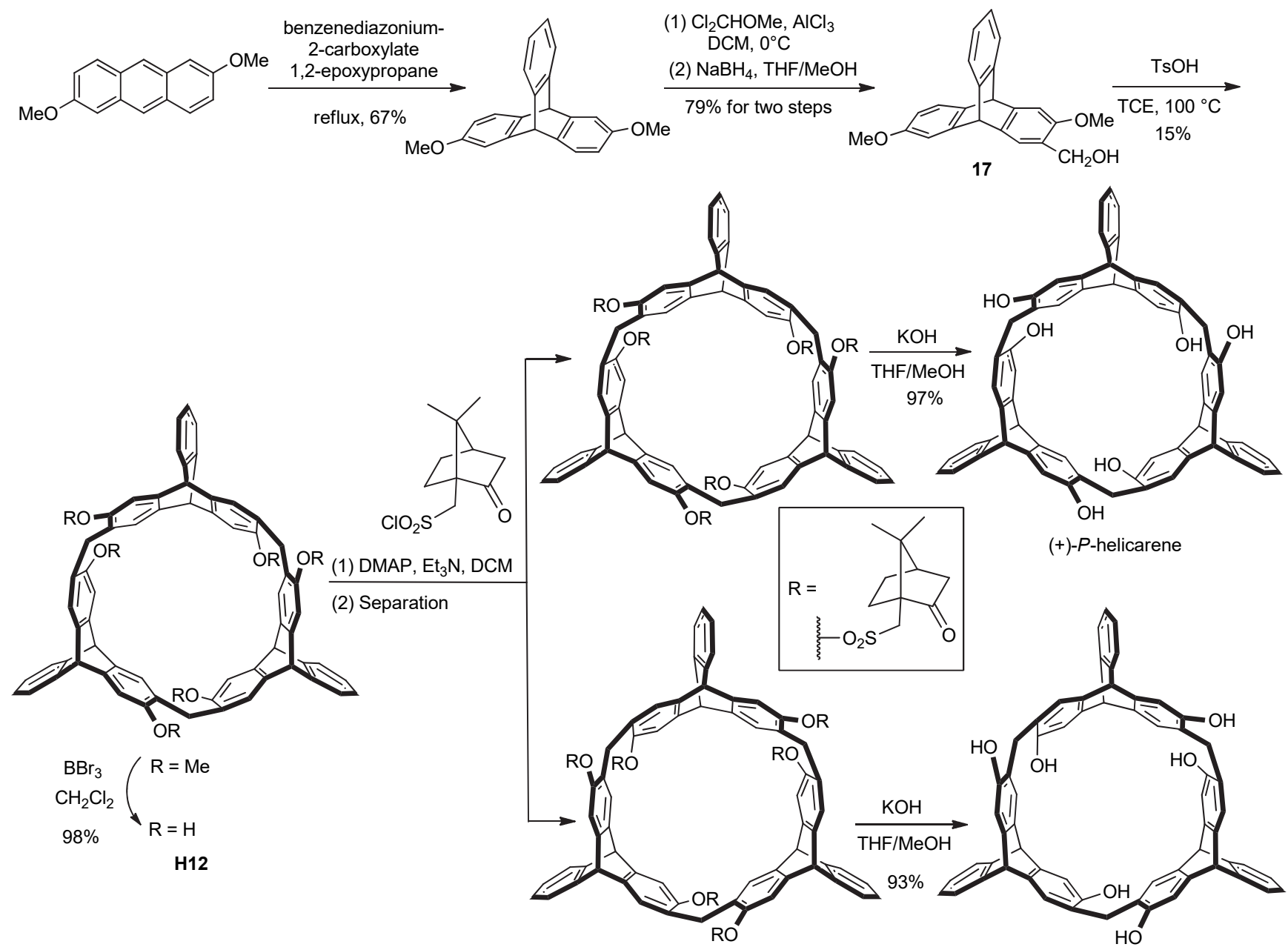

(-)-M-helicarene

图式 13 螺芳烃 $\mathrm{H12}$ 的合成与拆分

Scheme 13 Synthesis and resolution of helicarene $\mathbf{H 1 2}$ 


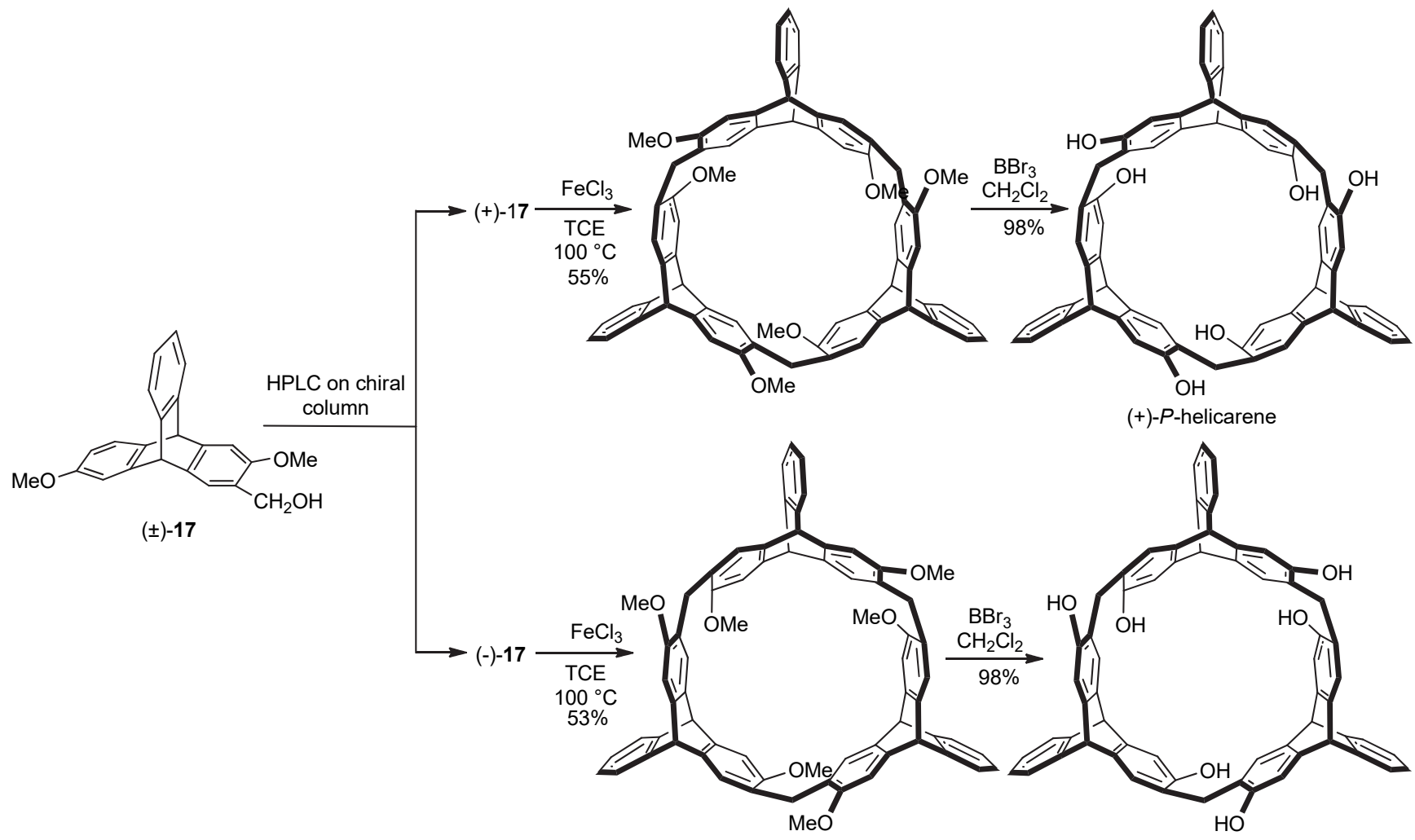

(-)-M-helicarene

图式 14 螺芳烃对映体的直接合成

Scheme 14 Direct synthesis of helicarene enantiomers

行溴代反应、醚化反应以及进一步的 Suzuki-Miyaura 偶 联反应等, 得到不同官能团化的螺芳烃衍生物 ${ }^{[33]}$, 为其 功能与应用研究奠定基础.

手性螺芳烃对于手性季铵盐客体分子 $\mathbf{G 1} \sim \mathbf{G 3}$ (图 2)显示出显著的对映选择性识别性能 ${ }^{[32]}$, 其中 $P-\mathbf{H 1 2}$ 对 手性䒢铵盐对映体 $R-\mathbf{G 1}$ 与 $S-\mathbf{G 1}$ 的选择性达到 $1: 6.67$. 螺芳烃与季铵盐、含 $N$ 杂环盐以及中性贫电子客体 G4 G19 也能够在溶液中或固态下形成 $1: 1$ 络合物 ${ }^{[34]}$. 螺芳烃还能够与碳正离子 $\mathbf{G 2 0}$ 在溶液中形成稳定的 1 : 1 络合物, 其主客体络合与解络合过程可通过氧化还原 调控, 同时这个过程还伴随着明显的颜色变化 ${ }^{[35]}$. 螺芳 烃与叔铵盐客体 $\mathbf{G 2 1} \sim \mathbf{G} 28$ 在溶液中也可以形成 $1: 1$ 络合物, 并且该主客体络合物的形成及解离 ${ }^{[36]}$ 能够通 过酸碱及氯离子的加入与除去进行有效调控 (Scheme 15, a). 基于这一络合作用, 我们进一步合成首例基于螺 芳烃的[2]轮烷. 螺芳烃与质子化 2-苯基吡啶盐 G29 G31 的络合过程不仅能够通过酸碱进行调控, 也可以在 基于螺吡喃的光酸存在下, 通过光对其进行有效调 控 ${ }^{\left[{ }^{[7]}\right.}($ Scheme 15, b). 此外, 与烷氧基取代的螺芳烃衍生 物相比, 差基取代的螺芳烃 H12 对联吡啶盐及质子化联 吡啶盐的络合能力更强, 并且与客体 $\mathbf{G} 32$ 的络合与解离 过程可通过酸碱调控 ${ }^{[38]}$.
由 $\mathrm{H12}$ 经过三步反应得到阳离子型水溶性螺芳烃 (Scheme 16), 其在水溶液中与季膦盐 $\mathbf{G 3 3} \sim \mathbf{G 3 5}$ 形成 $1: 1$ 络合物, 络合常数达到 $10^{5} \mathrm{~L} / \mathrm{mol}$ 以上, 并且络合 过程能够通过酸与碱进行调控 ${ }^{[39]}$. 最近, 马达课题组 ${ }^{[40]}$ 研究了 $\mathbf{H 1 2}$ 与 $\mathbf{G 3 6} \sim \mathbf{G} 37$ 等客体之间的主客体络合作 用，并基于 $\mathbf{H 1 2}$ 与 $\mathbf{G 3 6}$ 的主客体络合作用构筑一种超分 子囊泡, 发现该囊泡可负载并运输药物分子阿霉素 (G38) 至海拉细胞内, 在合适刺激下解组装并释放药物 从而杀死海拉细胞.

最近, 我们 ${ }^{[41]}$ 利用一对手性水溶性螺芳烃衍生物 $P-H 12 a$ 及 $M-H 12 a$ 与客体 $\mathbf{G 3 9}$ 形成的络合物进行组装, 制备了一种手性纳米粒子, 实现了手性由主体到客体的 转移, 并且发现纳米粒子的圆二色 $(\mathrm{CD})$ 以及圆偏振发光 (CPL)性质可通过酸碱进行有效地调控(图 3).

基于光酸能够调控螺芳烃与质子化吡啶盐之间的 络合过程, 我们 ${ }^{[42]}$ 进一步设计合成了三种轮烷型超分 子组装体, 研究发现该组装体中大环芳烃在质子化吡啶 盐及烷基链两个不同位点之间的穿梭或开关运动可以 在光酸存在下通过光诱导质子转移 (photo-induced proton-transfer, PIPT)进行有效地可见光调控(Scheme 17), 尤其是该光调控的开关运动能够重复 50 次以上没有显 著的效率变化. 
<smiles>C[N+](C)(C)C1CCc2ccccc21</smiles>

$R-\mathbf{G 1}$<smiles>C[N+](C)(C)C1CCc2ccccc21</smiles>

S-G1<smiles>COC(=O)C[C@H](C[N+](C)(C)C)OC(C)=O</smiles>

$R-\mathbf{G 2}$<smiles>COC(=O)C[C@H](C[N+](C)(C)C)OC(C)=O</smiles>

S-G2<smiles>CC(c1cccc2ccccc12)[N+](C)(C)C</smiles>

$R-\mathbf{G 3}$<smiles>CC(c1cccc2ccccc12)[N+](C)(C)C</smiles>

S-G3<smiles>CC(=O)OCC[N+](C)(C)C(F)(F)F</smiles>

G4

G5<smiles>CN(Cc1ccccc1)[P+](F)(F)F</smiles>

G7<smiles>C[N+](C)(C)Cc1cccc2ccccc12</smiles>

G8<smiles>C[N+](C)(C)c1cccc2ccccc12</smiles>

G9<smiles>C[N+](C)(C)c1ccc2ccccc2c1</smiles>

G10

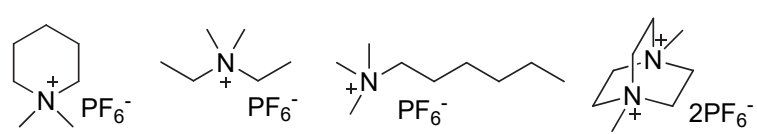
G11 G12<smiles>CCCC[n+]1ccccc1</smiles>

G15<smiles></smiles>
G16<smiles>C[n+]1ccc2ccccc2c1</smiles>

G17

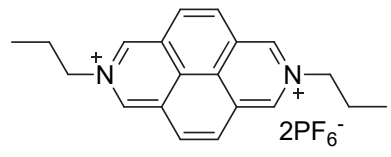

G18<smiles>CC(C)=c1ccc(=C(C)C(N)=[W])cc1</smiles>

G19

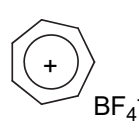

G20<smiles>C[N+](C)(c1ccc([N+](=O)[O-])cc1)C(F)(F)Br</smiles>

G21<smiles>CC[N+](Br)(CC)c1ccc([N+](=O)[O-])cc1</smiles>

G22

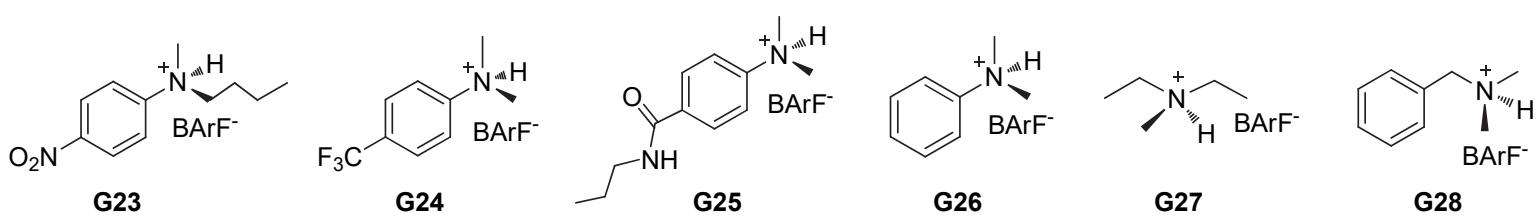

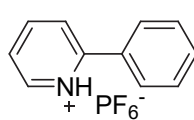

G29

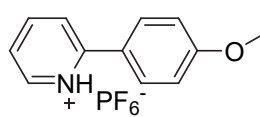

G30

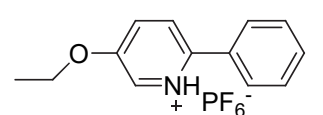

G31

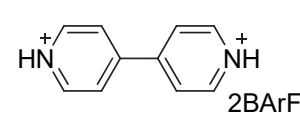

G32

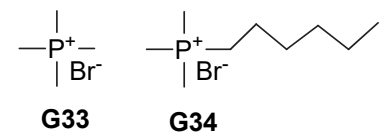

G34

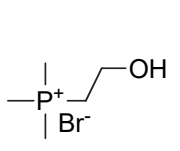

G35<smiles>CCCCCCCCNCC1CCC[C@H]1C1CC1</smiles>

G36<smiles>Cc1cc2nc3ccc(N(C)C)cc3nc2cc1NCl</smiles>

G37

图 2 客体分子结构式

Figure 2 Chemical structures of the guests

最近, 我们 ${ }^{[43]}$ 基于螺芳烃还设计合成了一种双稳 态[2]轮烷型组装体. 该组装体可通过氟离子的加入与 去除、酸与碱以及改变溶剂极性, 实现螺芳烃在两个不 同位点之间的开关运动. 利用类似的络合模式, 我们 ${ }^{[44]}$ 还发展了一种基于氟离子诱导封端基离去反应的单向 分子传输系统 (Scheme 18), 这为分子马达的设计构建 提供了一种新的策略.

最近, 我们 ${ }^{[45]}$ 发现了一个具有 $\mathrm{pH}$ 振荡特征的连续
化学反应(Scheme 19), 其中一个反应吸收酸, 另一个反 应能够释放酸. 将该 $\mathrm{pH}$ 振荡的化学反应用于螺芳烃与 质子化吡啶盐客体形成的互锁型分子机器中, 能够通过 在外加一次亚碘酰苯(化学燃料)之后, 自动地实现大环 在两个不同位点之间的一个往返运动(Scheme 20), 从 而有效地提高合成分子机器的能量利用效率和操作的 便捷性. 
(a)
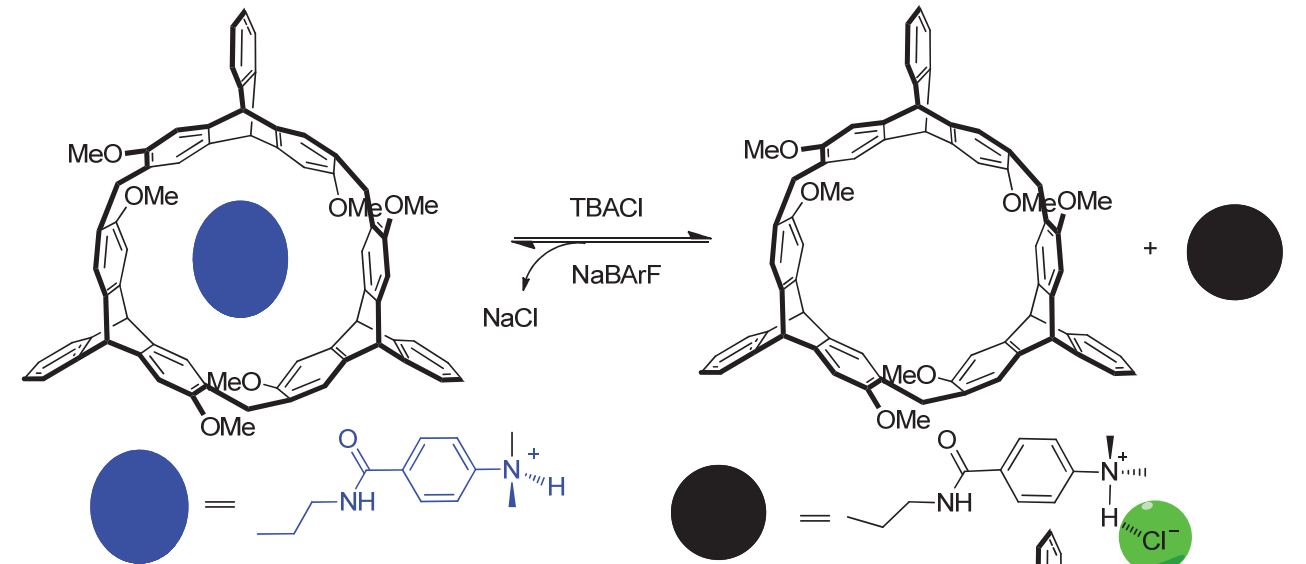

(b)
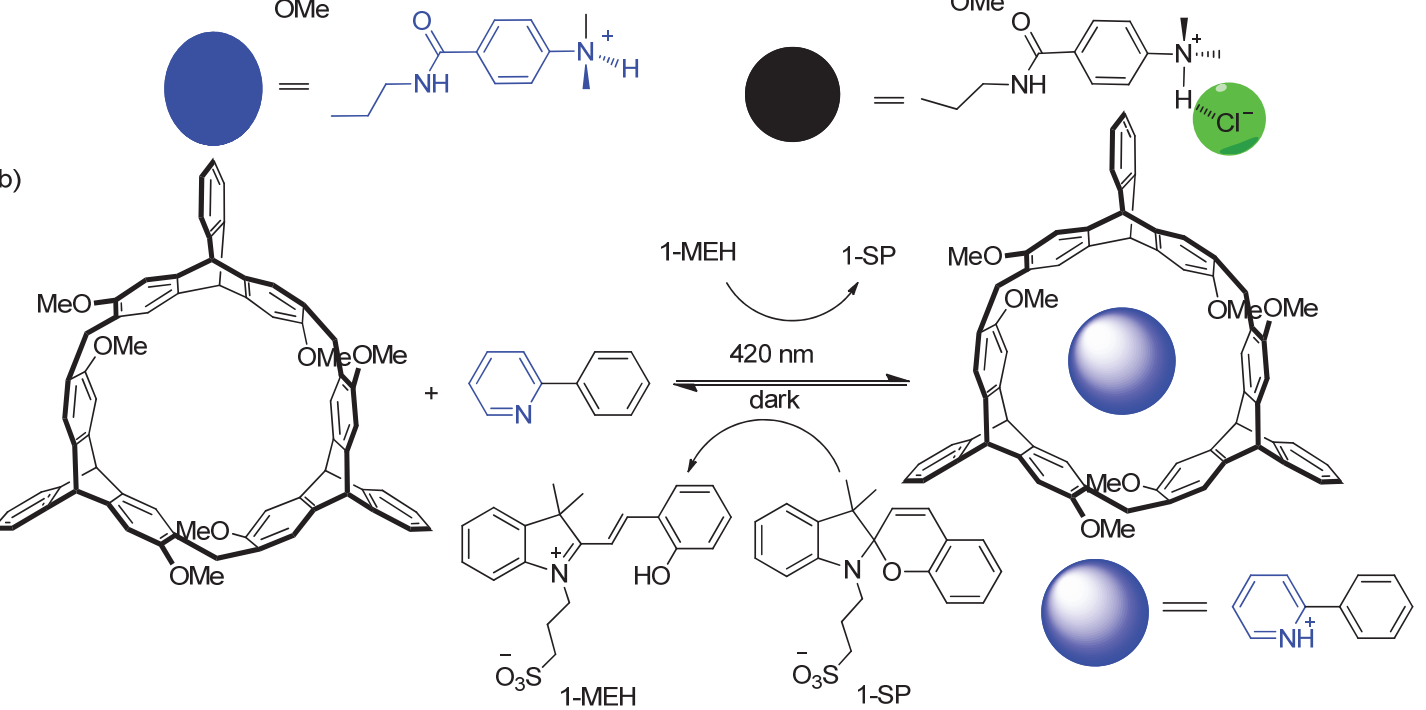

图式 15 通过(a)氯离子与(b)光酸调控的主客体络合过程

Scheme 15 Switchable complexation processes controlled by (a) $\mathrm{Cl}^{-}$ion and (b) photoacid
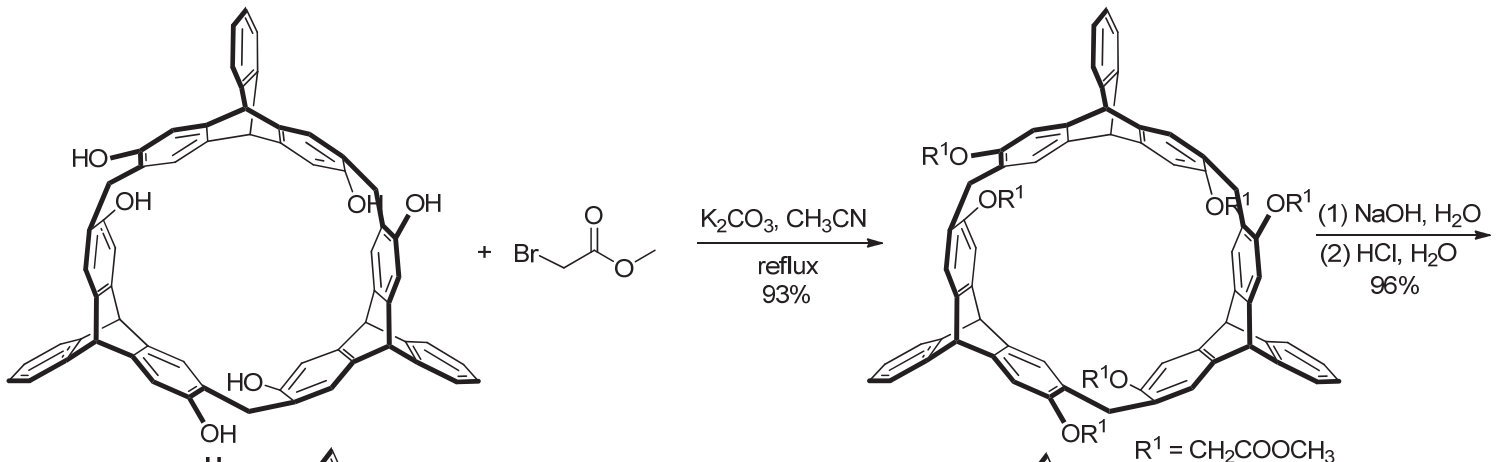

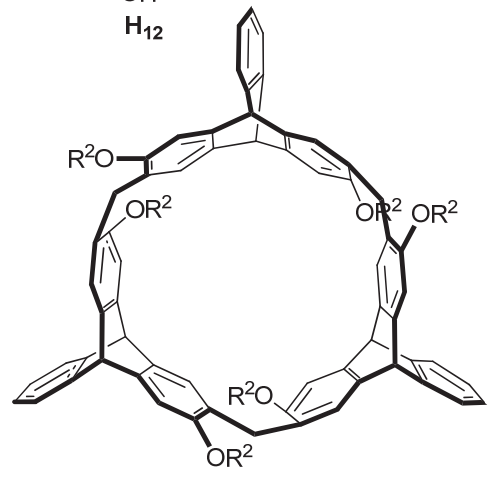

$\mathrm{R}^{2}=\mathrm{CH}_{2} \mathrm{COOH}$

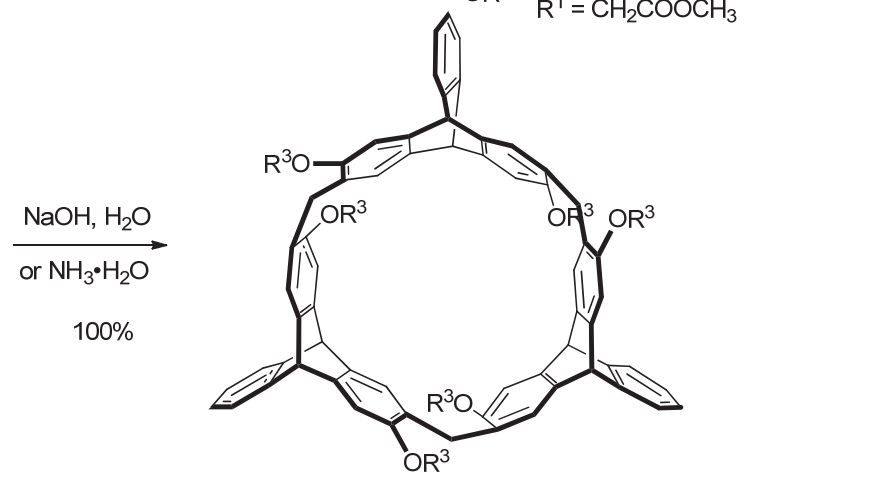

$\mathrm{R}^{3}=\mathrm{CH}_{2} \mathrm{COONa}, \mathrm{CH}_{2} \mathrm{COONH}_{4}$

图式 16 水溶性螺芳烃的合成路线

Scheme 16 Synthesis of water-soluble helicarenes 


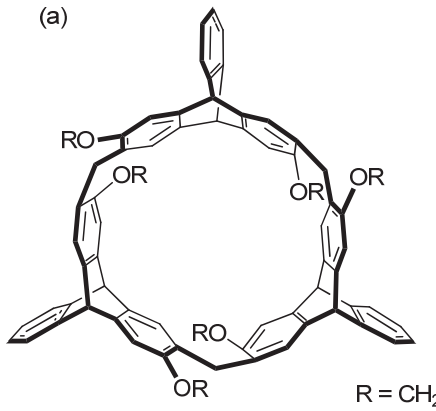

$(+)-P-H 12 a$

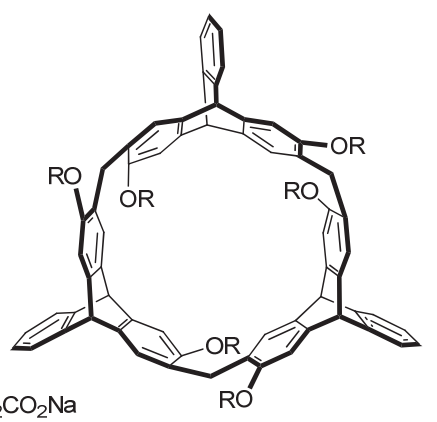

$(-)-M-H 12 a$

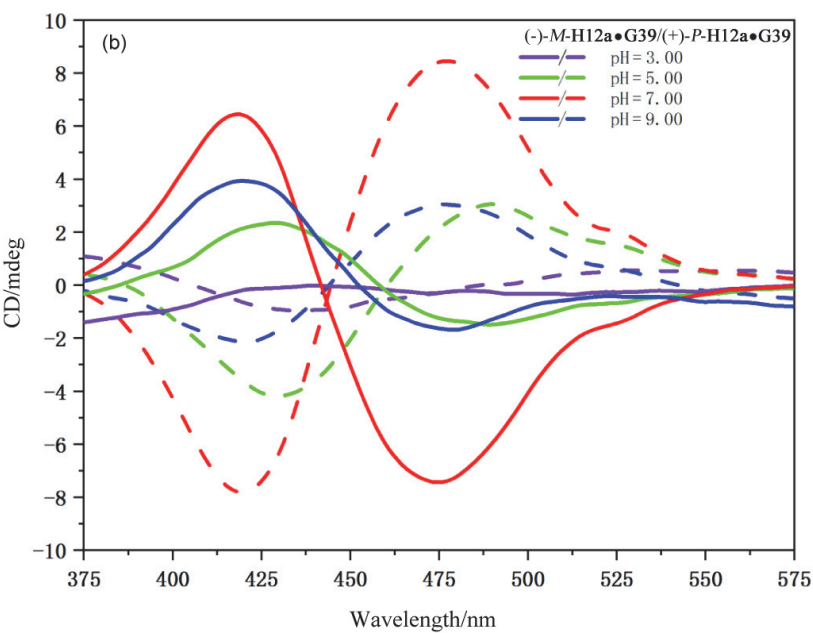

图 3 主体与客体的结构式(a)及组装体的酸碱可控 $\mathrm{CD}$ 性质(b)

Figure 3 Structures of hosts and guest (a) and CD properties of the assemblies in water with different $\mathrm{pH}$ values (b)

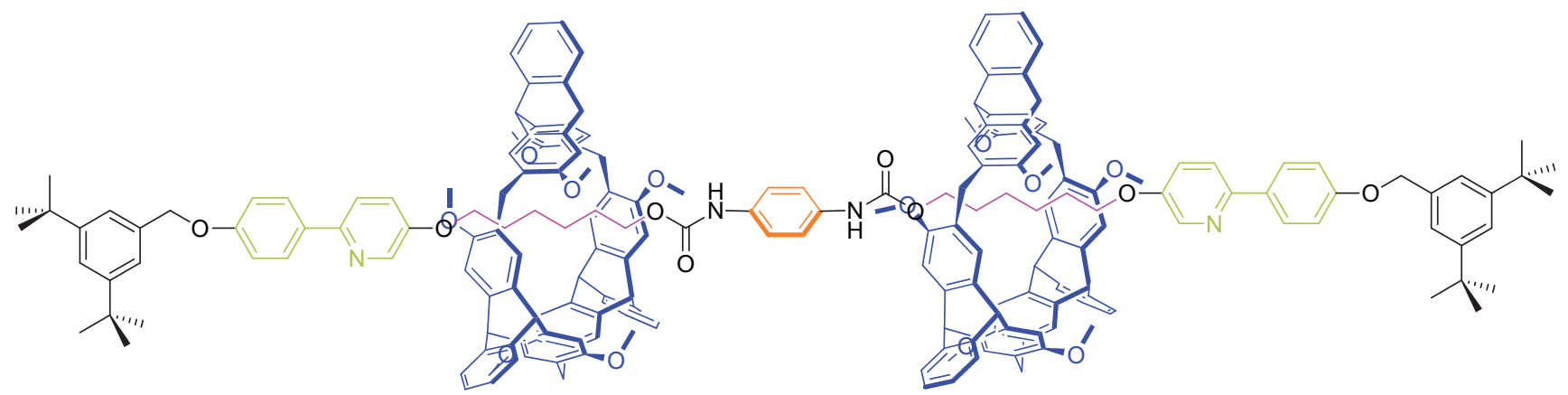

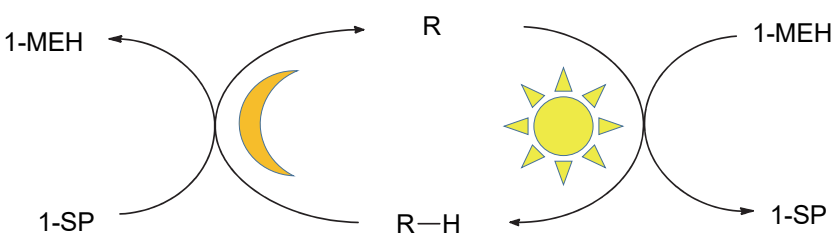

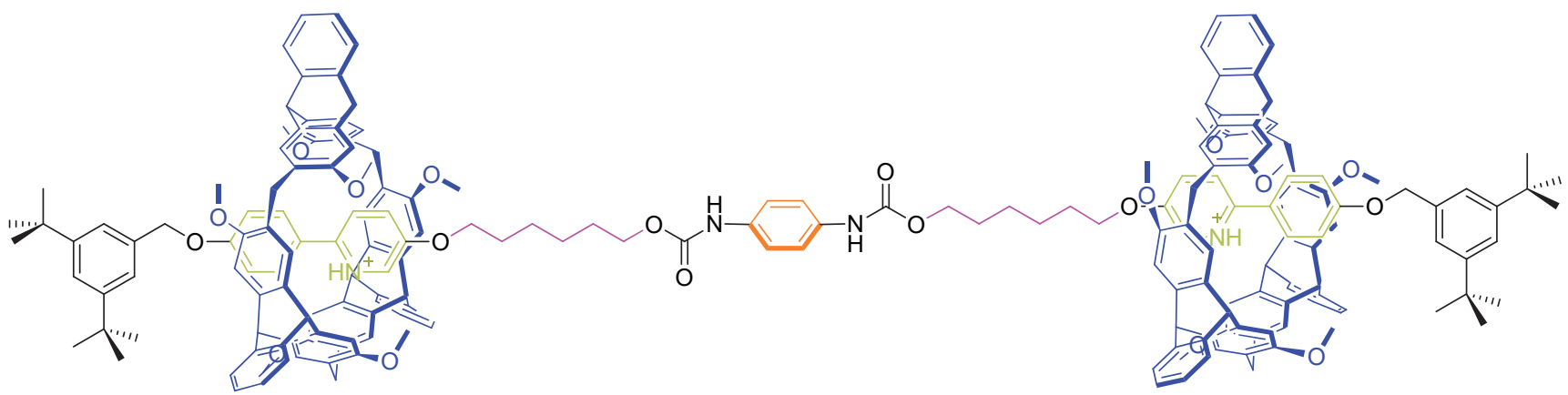

图式 17 基于 PIPT 策略的光驱动轮烷运动

Scheme 17 Photo-driven motion of rotaxane by PIPT strategy 


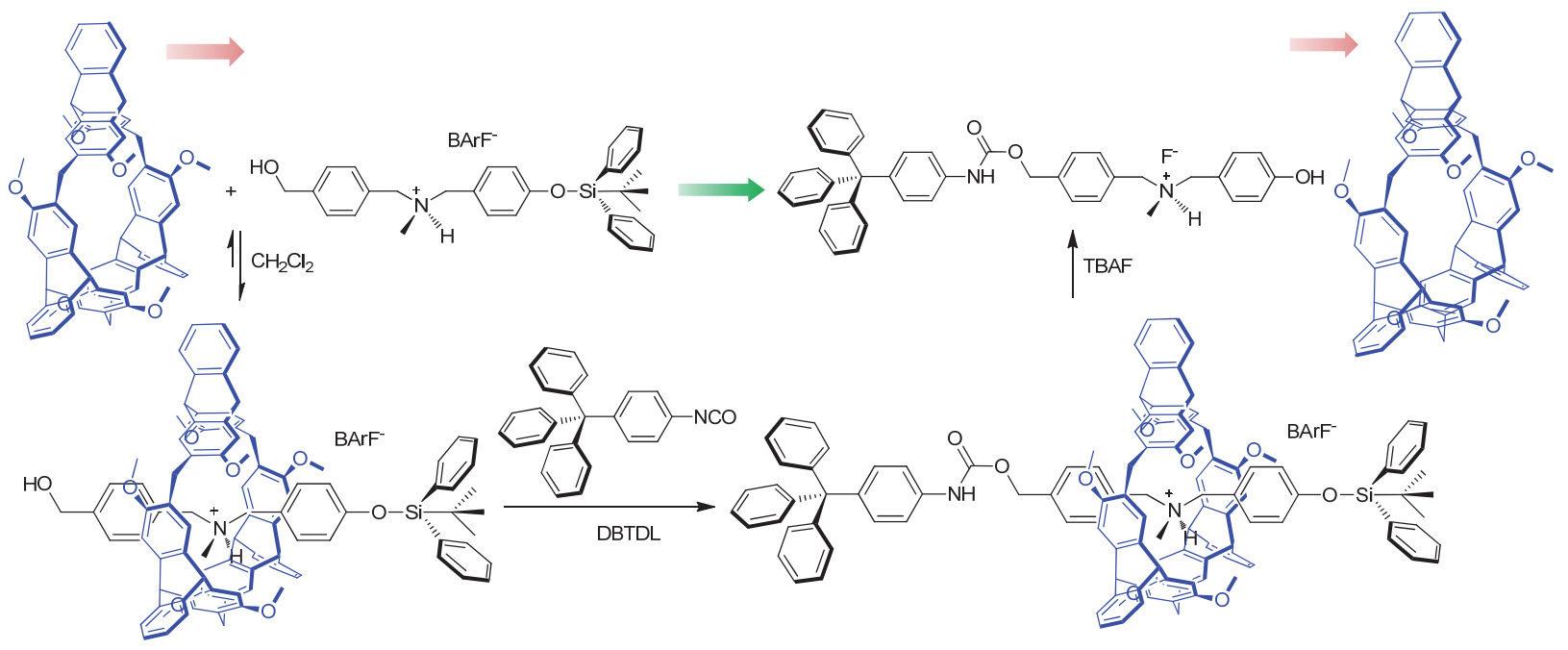

图式 18 单向分子传输系统

Scheme 18 A directional macrocycle transportation system

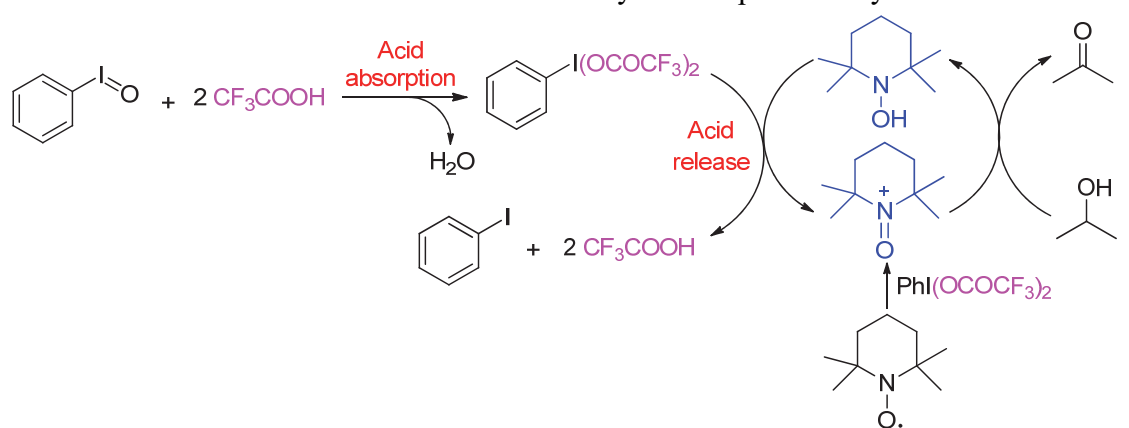

图式 19 TFA 吸收和释放的 PhIO 触发氧化还原循环

Scheme 19 PhIO triggered redox cycle with TFA absorption and release

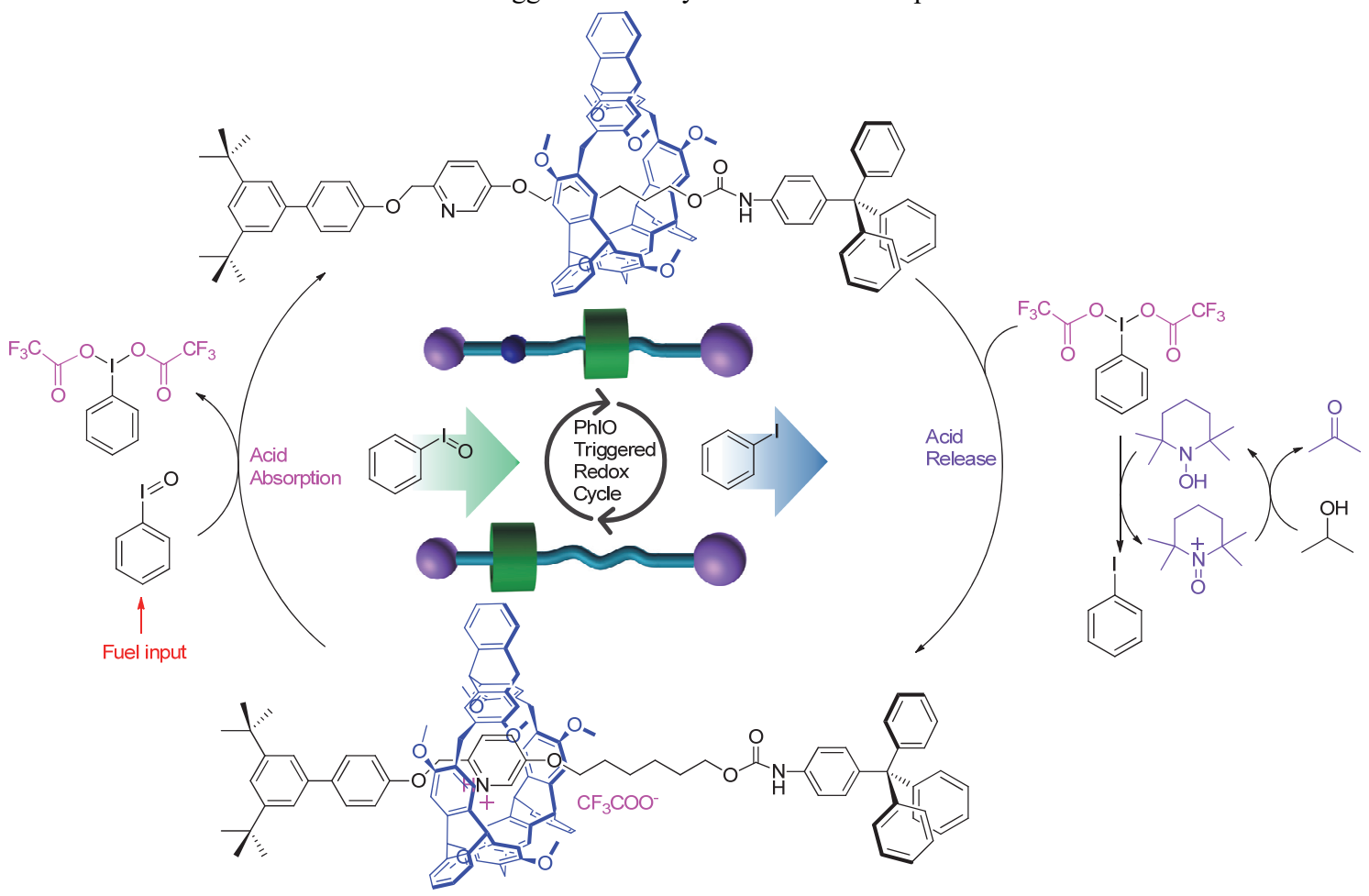

图式 20 亚碘酰苯引发的连续反应调控的轮烷运动

Scheme 20 Step-by-step reaction controlled motion of rotaxane triggered by $\mathrm{PhIO}$ 


\section{3 基于联苯基元的大环芳烃}

\section{1 联苯芳烃}

2015 年, 李春举等 ${ }^{[46]}$ 报道了一种新型大环芳烃, 其 命名为联苯芳烃(Biphen $[n]$ arenes, Scheme 21). 烷氧基 取代联苯 18 在三氟化嗍乙醚催化下与多聚甲醛缩合反 应，分别以 $22 \%$ 和 $8 \%$ 的产率得到联苯 [3]芳烃和联苯 [4] 芳烃. 单晶结构表明联苯 [3] 芳烃呈扭曲的三棱柱状, 联 苯[4]芳烃呈长方体状或者盒子状. 此外, 两种大环分子 组成基元呈不同排列方式: 联苯 [3]芳烃中联苯基元均 采取顺式构象, 而联苯 [4]芳烃中采取交错的顺式与反 式构象. 联苯芳烃对阳离子客体及中性缺电子客体均展 现识别性能.

黄飞鹤等 ${ }^{[47]}$ 通过联苯芳烃的衍生化, 得到阴离子 型水溶性联苯 [3]芳烃 H13a. 测试了水相中 H13a 对客 体分子 G40 的络合性质, 络合常数可达 $10^{4} \mathrm{~L} / \mathrm{mol}$. 进一 步研究表明向两亲体 G41 的溶液中加入 H13a, 溶液中 的组装体可实现胶束到纳米粒子的转变. 李春举等 ${ }^{[48]}$ 详细研究了 H13a 的主客体络合性质, 发现其对联吡啶 盐类客体 $\mathbf{G 4 2} \sim \mathbf{G} 47$ 有较强的络合作用. 由于电荷转移 作用, 主客体混合后溶液的颜色发生明显改变, 因此该 大环也可用于百草枯的裸眼检测.

喻国灿等 ${ }^{[49]}$ 合成了首例阳离子型水溶性联苯 [3]芳 烃 H13b, 发现 H13b 对客体 G48 $\sim$ G50 显示良好的络合 性能, 络合常数在 $10^{2} \sim 10^{3} \mathrm{~L} / \mathrm{mol}$ 之间, 推测驱动力主 要是疏水作用及静电相互作用. 基于 $\mathbf{H 1 3 b}$ 与两亲性客 体 G54 的相互作用进行了进一步的组装研究, 结果表明 G54 可在水中自组装成小的球形胶束, 当向其中加入
H13b 后，形成的主客体复合物可组装成更大尺寸的纳 米粒子(图 4). 2016 年, 李春举等 ${ }^{[50]}$ 报道了羟基联苯[4] 芳烃的主客体络合性质，发现主体分子对体积较大的金 刚烷客体 G51 及二茂钴客体 G52 有较强的络合作用. 他 们 ${ }^{[51]}$ 进一步合成了羧酸根衍生的水溶性联苯 [4]芳烃 H13c，并发现其对乙酰胆碱的主客体络合过程可通过 酸碱进行调控.

采用类似的合成方法, 李春举等 ${ }^{[52]}$ 得到了一系列 2,2'-联苯芳烃 H14 (2,2'-Biphen[ $n]$ arenes). 如 Scheme 22 所示, 由 $2,2^{\prime}$ 二二乙氧基取代联苯 19 出发, 以 $51 \%$ 的总产 率分离得到五种新的大环芳烃: 环四聚体到环八聚体. 他们同时还尝试 3,3'二乙氧基取代联苯 20 的环化反应, 但是没有得到成环产物，原因可能是取代基的邻对位均 为活性位点, 导致反应过程复杂从而无法得到目标的成 环产物. $\mathbf{H 1 4}$ 对客体 $\mathbf{G 5 5} \sim \mathbf{G 5 7}$ 的络合常数均在 $10^{2} \sim$ $10^{4} \mathrm{~L} / \mathrm{mol}$ 之间. 该课题组 ${ }^{[33]}$ 通过 $2,2^{\prime}$-联苯 [4]芳烃衍生 化, 得到一种羧酸修饰的水溶性大环 $\mathrm{H14a}$, 在磷酸盐 缓冲溶液中测试了其对两种生物碱巴马汀 $\mathbf{G 5 8}$ 以及黄 连素 G59 的络合作用. 核磁及苂光光谱证明了主客体络 合物的形成, 络合常数可达 $10^{6} \mathrm{~L} / \mathrm{mol}$. 另外, 在客体溶 液中加入大环分子后, 溶液出现显著的荧光增强现象, 肉眼可以辨别.

2019 年, 李春举等 ${ }^{[54]}$ 由 21 出发, 通过一锅煮方法 以 99\%的产率得到 2,2',4,4'-四甲氧基联苯 [3]芳烃 $\mathbf{H 1 5}$ $\left(2,2^{\prime}, 4,4^{\prime}\right.$-tetramethoxylated biphen[ $\left.n\right]$ arenes $)$ 与 H13 与 H14 相比, H15 组成基元的取代基数目由两个增加到了 四个, 产率大大提高(Scheme 23). 溶剂影响环聚体的种 类及产率, 溶剂为二氯甲烷、乙腈时, 可分别以 $98 \%$ 和

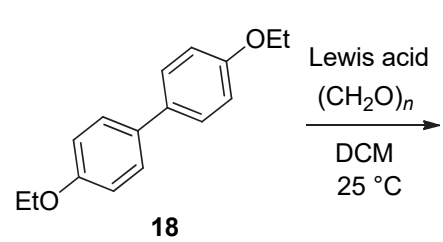

18
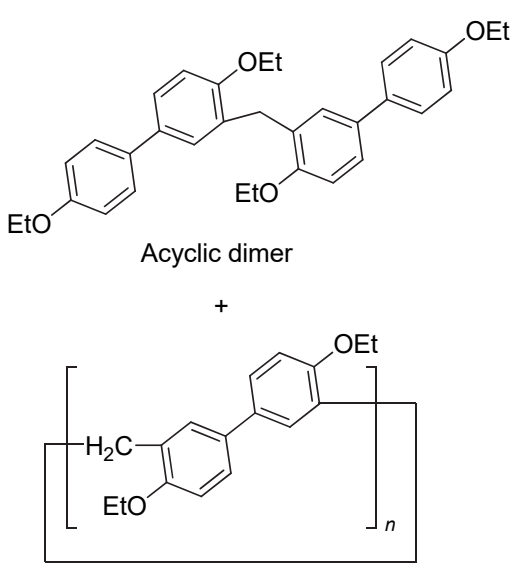

H13 Biphen[ $n]$ arene $(n=3,4)$

$+$

Polymers

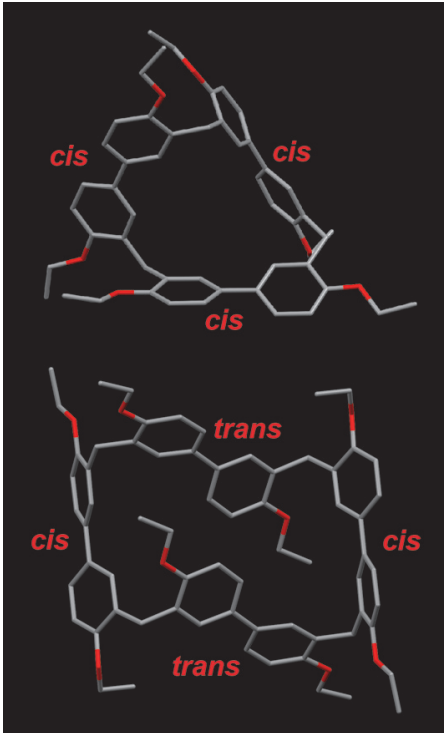

图式 21 对乙氧基联苯 $[n]$ 芳烃的合成及其晶体结构

Scheme 21 Synthesis of per-ethoxylated biphen[ $n]$ arenes and their crystal structures 

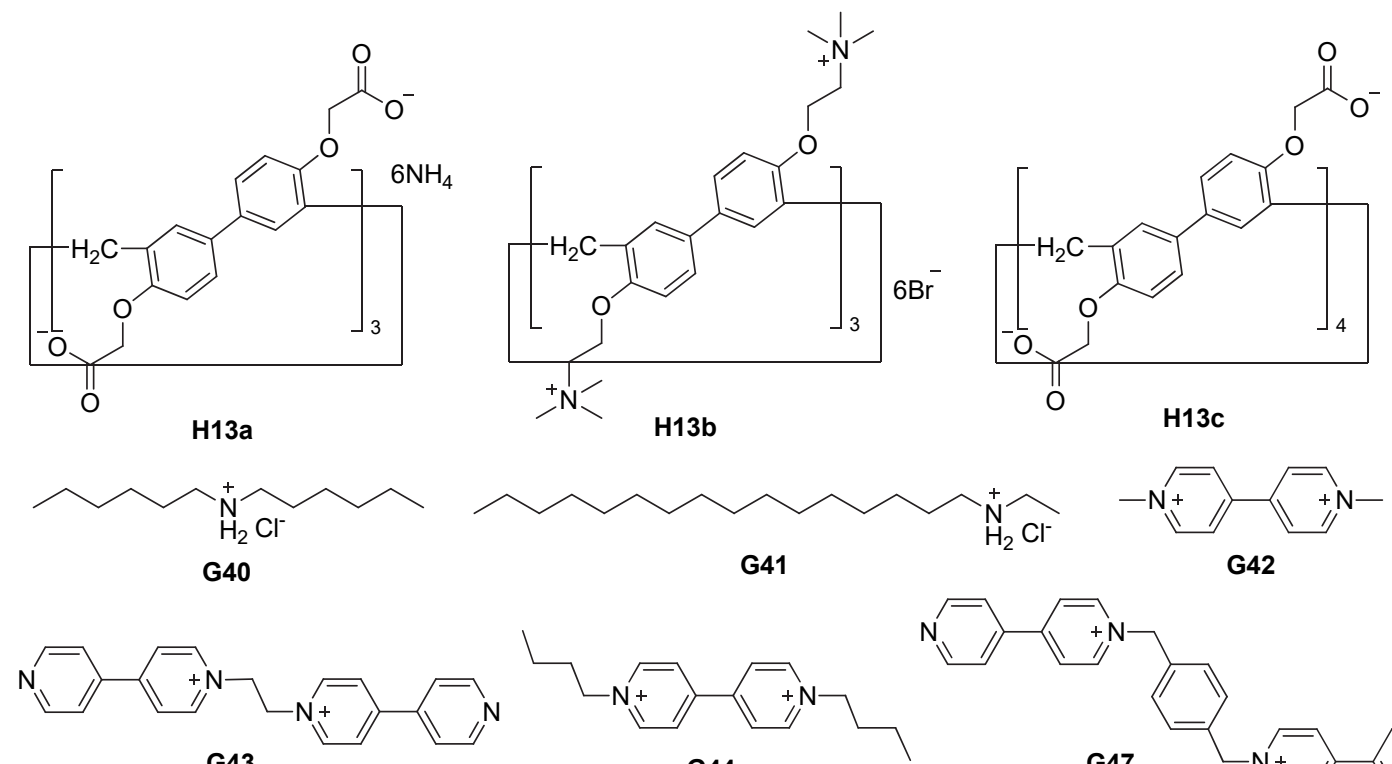

G43
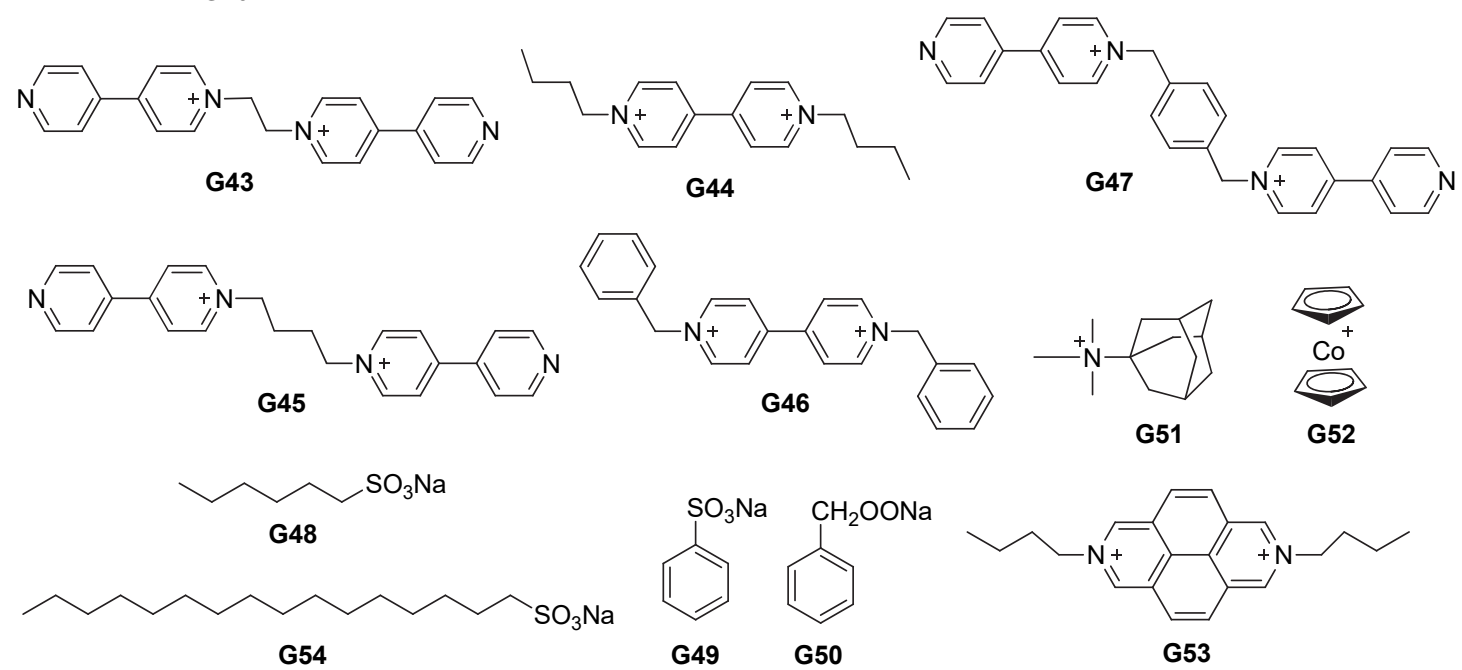

图 4 水溶性联苯芳烃及客体的结构式

Figure 4 Structures of water-soluble biphenarenes and guests<smiles>CCOc1ccccc1-c1ccccc1OCC</smiles>

19<smiles>CCOc1ccc(CC=C(C)Cc2ccc3c(OCC)cccc3c2)cc1OCC</smiles><smiles>[NH3+]Cc1ccccc1</smiles>

G55<smiles>[NH3+]Cc1cccc2ccccc12</smiles>

G56

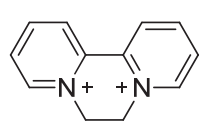

G57

H14 $(n=4 \sim 8)$

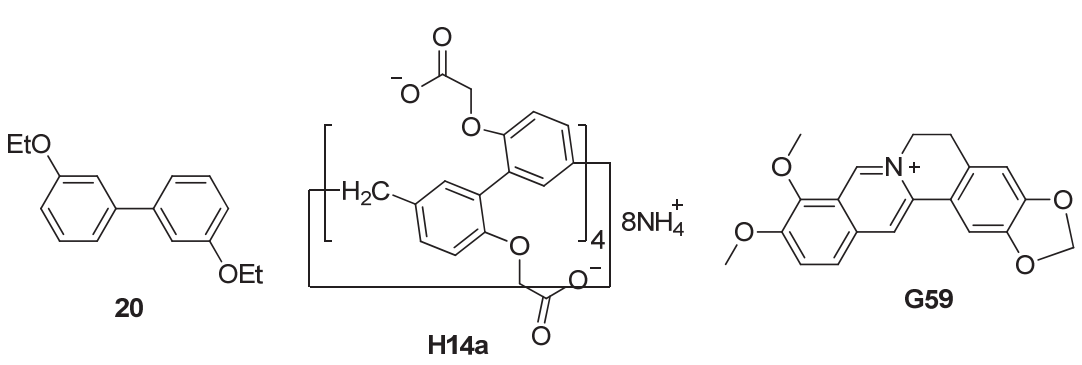

图式 $222,2^{\prime}$-联苯芳烃的合成及客体结构式

Scheme 22 Synthesis of 2,2'-biphenarene and chemical structures of guests 


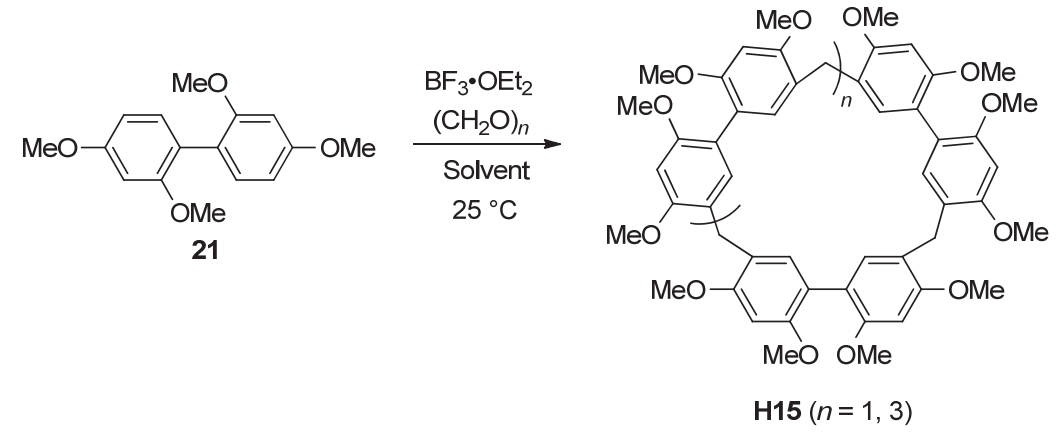

图式 $232,2^{\prime}, 4,4^{\prime}$-四甲氧基联苯 $[n]$ 芳烃的合成

Scheme 23 Synthesis of 2,2',4,4'-tetramethoxylated biphen $[n]$ arenes

99\%的产率得到环三聚体; 溶剂为二氯乙烷时, 可以 $5 \%$ 的产率得到环五聚体, 而此时环三聚体的产率为 54\%. 单晶结构表明大环 $\mathrm{H15}$ 呈三角形状, 空腔大小为 $0.543 \mathrm{~nm}$. 晶态的联苯 [3]芳烃可选择性地吸附顺式二氯 乙烯, 单次吸附实验中顺式二氯乙烯纯度可达 $96.4 \%$ (起 始顺式反式二氯乙烯体积比为 $1: 1$ ). 单晶及粉末衍射 研究表明客体的进入会诱导主体结构的转变, 这体现了 联苯芳烃自适应性的特点.

\section{2 多苯芳烃}

采用类似的合成方法, 李春举等 ${ }^{[55]}$ 以 $41 \%$ 和 $35 \%$ 的 总产率合成得到了三苯芳烃 TPns (Terphen $[n]$ arenes) 以 及四苯芳烃 QPns (Quaterphen[n]arenes) (Scheme 24). 与 H13、H14、H15 相比, 此两类大环分子在空腔尺寸 上独具优势, 其中 $\mathbf{Q P 6}$ 空腔大于 $3.0 \mathrm{~nm}$. 两类大环的环 五聚体与环六聚体均可在二氯甲烷和环己烷的混合溶 液中形成凝胶, 这可能由于分子间的 $\pi \cdots \pi$ 堆积作用有 利于自组装体进一步组装形成凝胶. 通过湿凝胶在真空 干燥箱 $80{ }^{\circ} \mathrm{C}$ 干燥得到的干凝胶, 不仅在液态而且在气 态下均能够作为吸附碘的材料, 对碘的吸附可归因于碘 与苯环之间的电荷转移作用.

最近, 李春举等 ${ }^{[56]}$ 利用模块化合成策略得到了一 系列功能大环主体分子(Scheme 25), 其中包括分别含
有䒺、萠、葱醌、卟啉等功能基团的大环分子. 环化过 程因前体结构而异: 利用线性前体 23 得到环三聚体和 环四聚体，而基于 $\mathrm{V}$ 型前体 24 则得到环二聚体. 大环分 子的后修饰反应也较为便捷. H17a 单晶结构显示大环 分子为消旋体, 存在两对对映体, 具有不同的边长和扭 转角.

\section{3 杯 $[2]$ 联苯[1]类杂[3]芳烃}

2016 年, 喻国灿等 ${ }^{[57]}$ 报道了一个新的大环芳烃杯 [2] 联苯 [1]类杂 [3]芳烃 ([2]Calix[1]biphenyl-type Hybrid[3]arene). 如 Scheme 26 所示, 由 25 及 $\mathbf{2 6}$ 出发, 在 三氟乙酸催化下回流 $30 \mathrm{~min}$, 可以 $25 \%$ 的产率得到 H19. 延长反应时间会得到分子量更大的杂 $[2+3]$ 芳烃及杂 [4 +2 ]芳烃，只能通过质谱表征，核磁峰过于杂乱无法完 成结构表征. $\mathrm{H19}$ 对客体分子 $\mathrm{G}_{60}$ 的络合常数为 $10^{2}$ $\mathrm{L} / \mathrm{mol}$. 最近, 黄飞鹤与喻国灿等 ${ }^{[58]}$ 基于晶态 $\mathbf{H 1 9}$, 实现 了苯(Bz)及环己烷(Cy)的分离. 将活化后的 $\mathbf{H 1 9}$ 晶态材 料置于 $\mathrm{Bz}$ 与 $\mathrm{Cy}$ 体积比为 $1: 1$ 混合气氛中, 发现 $\mathrm{H19}$ 可以 $97.5 \%$ 的纯度实现 $\mathrm{Bz}$ 的分离. 吸附 $\mathrm{Bz}$ 的晶态材料 被加热后可将 $\mathrm{Bz}$ 释放, 之后再用于 $\mathrm{Bz}$ 及 $\mathrm{Cy}$ 的分离纯 化(Scheme 26). 该材料可重复利用 10 次以上, 具有较 高的可重复利用率.
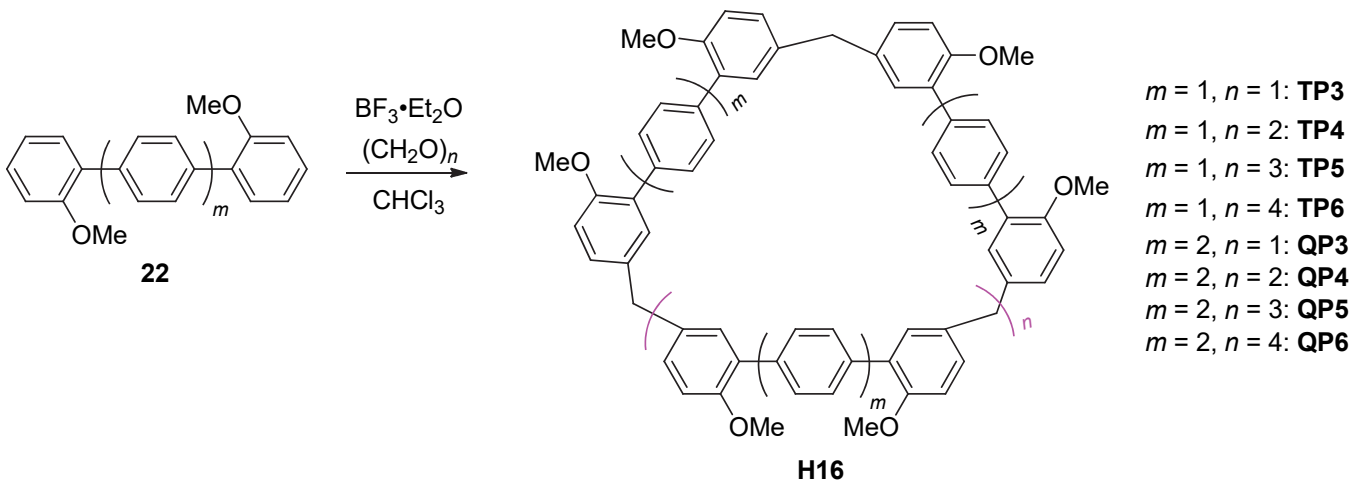

图式 24 三苯芳烃和四苯芳烃的合成

Scheme 24 Synthesis of terphen $[n]$ arenes and quaterphen $[n]$ arenes 

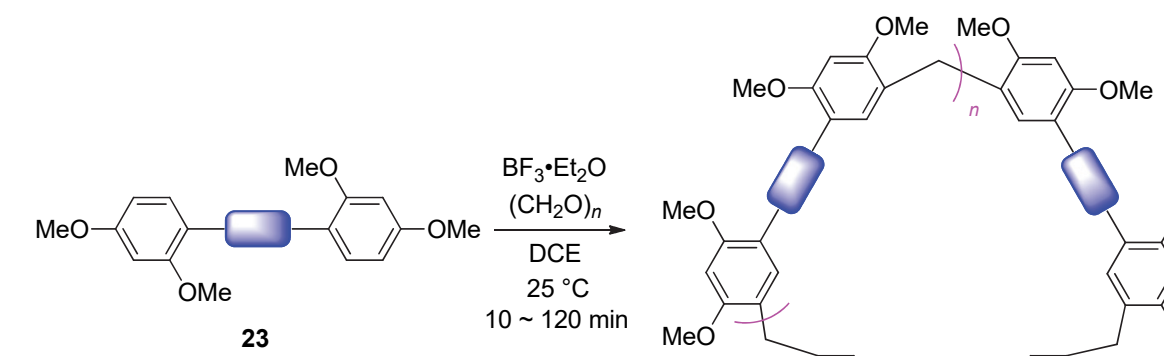

$\mathrm{MeO}$
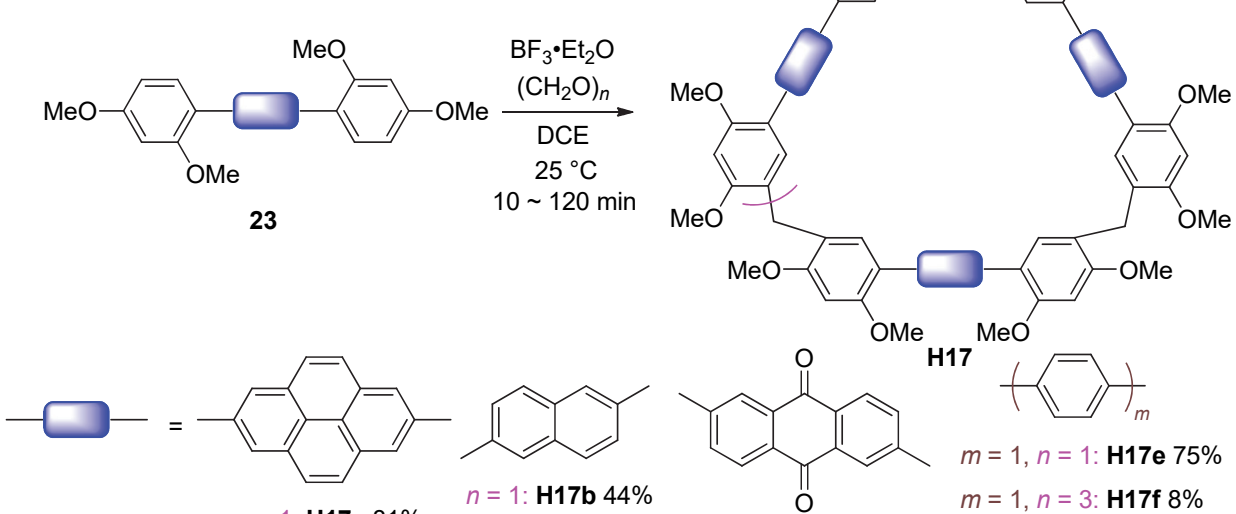<smiles>Cc1ccc2c(c1)C(=O)c1ccc(C)cc1C2=O</smiles>

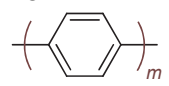

$n=1: \mathbf{H} 17 \mathbf{a} 81 \%$

$n=1: \mathbf{H 1 7} \mathbf{b} 44 \%$

$n=3:$ H17c 4\%

$m=1, n=1: \mathbf{H} \mathbf{1 7 e} \mathbf{7 5} \%$

$m=1, n=3: \mathbf{H 1 7 f} \mathbf{8 \%}$

$n=1: \mathbf{H} \mathbf{1 7} \mathbf{d} 29 \%$

$m=2, n=1: \mathbf{H} \mathbf{1 7 g} 86 \%$

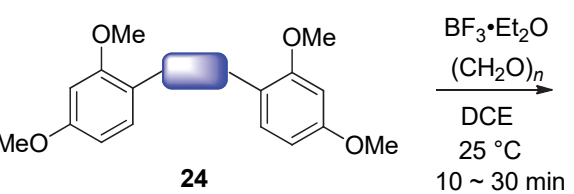<smiles></smiles>
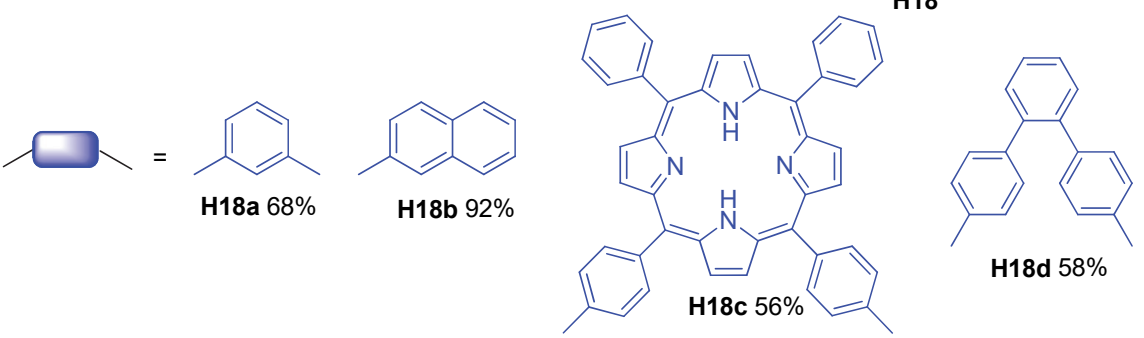

H18d 58\%

图式 25 由线性单体及 V-型单体合成大环

Scheme 25 Synthesis of the macrocycles from linear monomers and V-shaped monomers

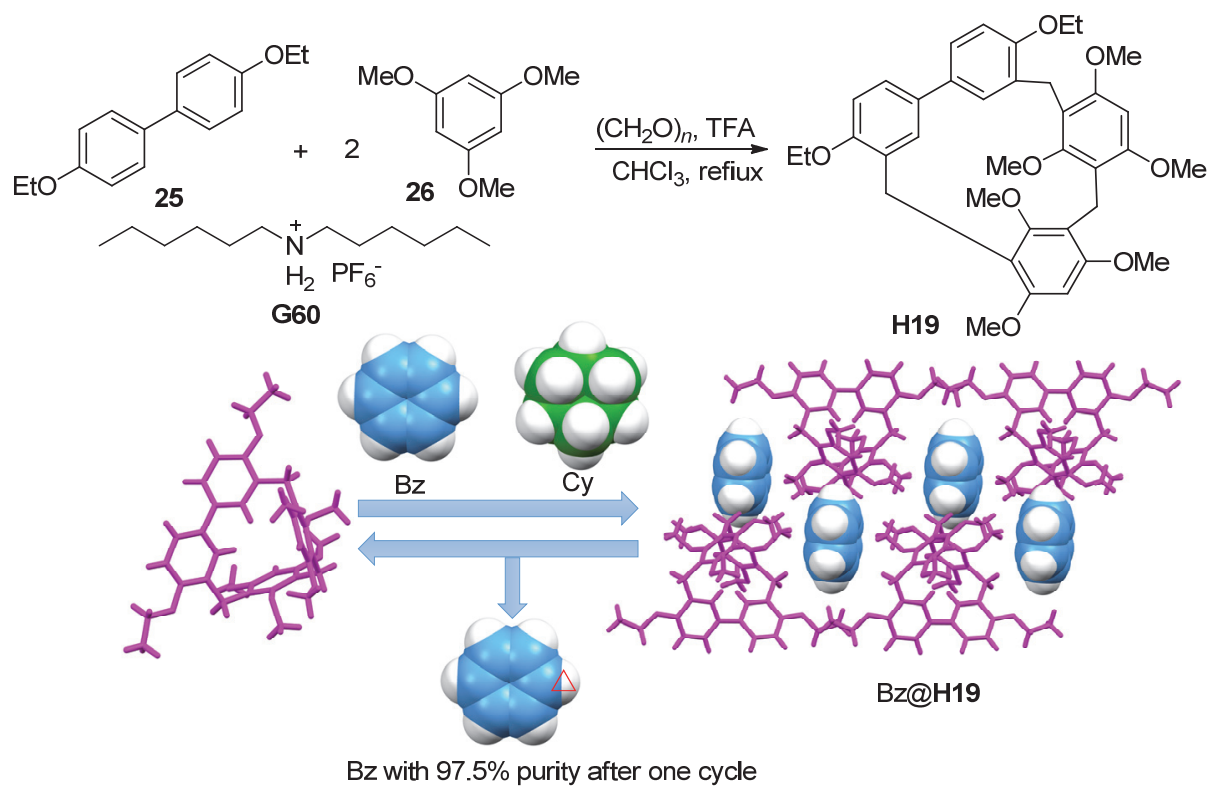

图式 26 杯[2]联苯[1]类杂[3]芳烃的合成及吸附分离性质

Scheme 26 Synthesis of [2]calix[1]biphenyl-type hybrid[3] arene and its adsorptive separation properties 


\section{4 基于咔唑基元的大环芳烃}

杨鹏等 ${ }^{[59]}$ 由咔唑衍生物 27 出发, 在二氯甲烷为溶 剂、六水合三氯化铁为催化剂条件下与多聚甲醛缩合反 应, 以 $20 \%$ 的产率得到杯 [3]咔唑(Calix[3]carbazole) (Scheme 27). 更大的环聚体如杯 [4] 杯 [6]咔唑亦能够 生成, 但由于纯化困难, 因而未做进一步研究. 杯[3]咔 唑可形成一端封闭的雉形结构, 与钾离子通道大小相 当, 此外该大环具有较深的富电子空腔, 对体积较大的 四乙基氯化铵客体具有较好的络合性质, 在有机体系中 络合常数可达 $10^{2} \mathrm{~L} / \mathrm{mol}$.

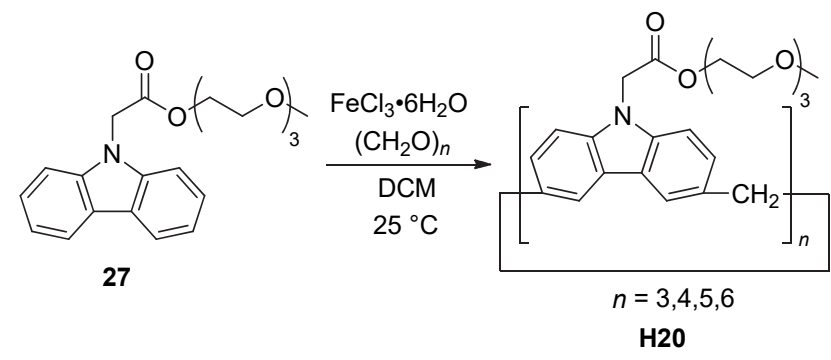

图式 27 杯咔唑的合成

Scheme 27 Synthesis of calix $[n]$ carbazoles

从杯 [4]咔唑出发, 杨鹏等 ${ }^{[60}$ 通过两步反应得到阳 离子型水溶性杯[4]咔唑 H20a (Scheme 28). 由于咔唑基 元的引入, H21a 具有苂光. 核磁及分子模拟研究表明 H21a 呈 1,3 交替式构象, 在水中可与有害的工业材料双 酚 $\mathrm{F}$ 形成 $1: 1$ 络合物, 能够作为检测双酚 $\mathrm{F}$ 的荧光探 针，检测限可达 $10^{-7} \mathrm{~mol} / \mathrm{L}$.

二价铜离子催化 $\mathrm{C}-\mathrm{H}$ 键活化研究颇多, 但但有关 该过程的可视化研究以及可逆性研究报道却较少. 2017 年, 杨鹏课题组 ${ }^{[61]}$ 将杯 [3] 咔唑与二价铜离子络合与解 离的过程作为传感器用于 $\mathrm{C}-\mathrm{H}$ 键的断裂与生成的可视 化检测. 杯[3]咔唑与二价铜离子络合后, 桥连亚甲基上 的 $\mathrm{C}-\mathrm{H}$ 键裂解, 从而产生碳正离子中间体, 此时溶液 为蓝色. 向溶液中加入更强的配体三亚乙基四胺后, 二 价铜离子被剥离, 碳正离子中间体又转变成初始的杯 [3] 咔唑(Scheme 29). 质谱检测到的碳正离子中间体, 电
子顺磁共振波谱检测到了产生的一价铜离子, 为 $\mathrm{C}-\mathrm{H}$ 活化反应机理提供了佐证. 基于这一现象，该杯[3]咔唑 可作为检测二价铜离子的可视化传感器.

杨鹏课题组 ${ }^{[62]}$ 利用水溶性杯 [4]咔唑具有类似亮氨 酸拉链形状的特点, 将其作为客体与 DNA 的 A 片段结 合，通过紫外、苂光、圆二色谱及核磁等方法表征了该 络合过程. TWJ-DNA 是 DNA 复制及重组过程中的中间 产物, 在生命过程中扮演重要角色. 最近, 杨鹏等 ${ }^{[63]}$ 合成 了水溶性杯 [3]咔唑, 并利用紫外、苂光、圆二色谱、凝 胶电泳及核磁等研究了其与 TWJ-DNA 的结合作用, 结 果表明该大环主体可以选择性地与 TWJ-DNA 结合, 驱 动力是疏水效应及尺寸匹配效应. 基于大环分子的苂光 性质，该杯[3]咔唑可用作检测 TWJ-DNA 的苂光探针.

\section{5 基于慕环基元的大环芳烃}

\section{1 杯[4]慕芳烃}

2016 年, Szumna 等 ${ }^{[64]}$ 通过 1,6-二甲氧基薺 28 与甲 醛在二氯乙烷为溶剂、三氟乙酸(TFA)为催化剂条件下 缩合反应，以 $15 \%$ 产率得到两个杯[4]菜芳烃异构体大 环(Calix[4]naphthalenes, Scheme 30). 由于菜基元的引 入使得两个大环具有加深的富电子空腔与柔性结构, 在 溶液中对吡啶盐及咪唑盐客体均具有较强络合性能.

\section{2 棱芳烃}

最近, Gaeta 等 ${ }^{[65]}$ 通过 2,6-二甲氧基萗 29 与甲醛在 TFA 催化下缩合反应，得到了三种棱芳烃(Prismarenes, Scheme 31): 棱[5]芳烃 H22a、1,4- $C$-棱[5]芳烃 H22b 以 及棱[6]芳烃 H22c. 以二氯乙烷为溶剂可以 $40 \%$ 产率得 到 $\mathbf{H 2 2 b}$, 当向溶液中加入合适模板离子后可分别得到 H22a (产率 47\%) 与 H22c (产率 20\%). 将 H22a 置于 $70{ }^{\circ} \mathrm{C}$ 的二氯乙烷中 $16 \mathrm{~h}$ 后可完全转化为 $\mathbf{H 2 2 b}$, 结果表 明 $\mathrm{H22} \mathrm{a}$ 是动力学产物, $\mathrm{H22b}$ 是热力学产物. H22c 也可 在高温下转化为 $\mathbf{H 2 2 b}$. 棱[5]芳烃具有加深的富电子空 腔, 可通过阳离子 $\cdots \pi$ 和 ${ }^{+} \mathrm{NC}-\mathrm{H} \cdots \pi$ 作用对季铵盐客体 显示优异的主客体络合性质, 络合常数最高可达 $10^{7}$ $\mathrm{L} / \mathrm{mol}$.

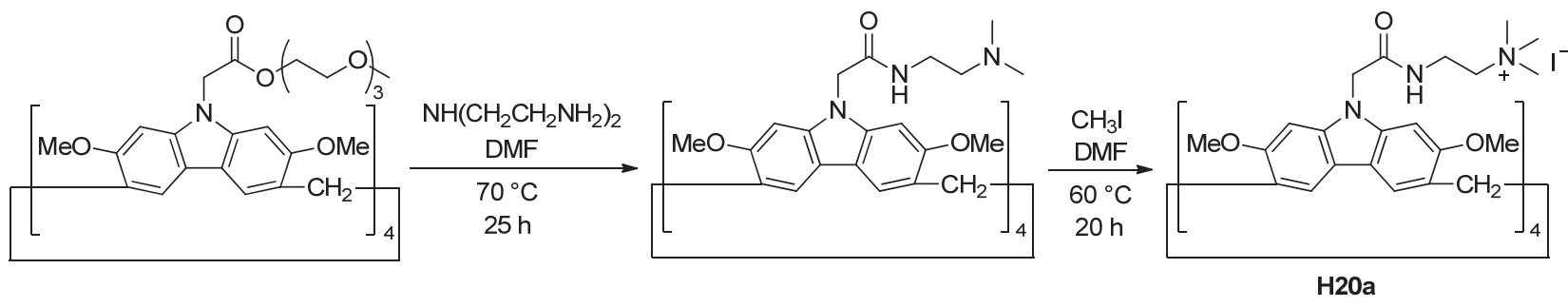

图式 28 水溶杯 [4]咔唑的合成

Scheme 28 Synthesis of water-soluble calix[4]carbazole 


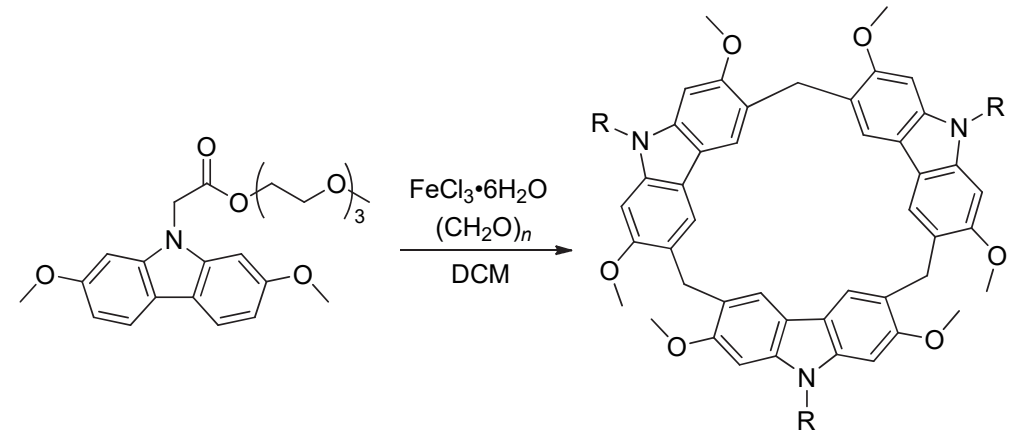

$\mathrm{R}=\mathrm{CH}_{2} \mathrm{COO}\left(\mathrm{C}_{2} \mathrm{H}_{4} \mathrm{O}\right)_{3} \mathrm{CH}_{3}$
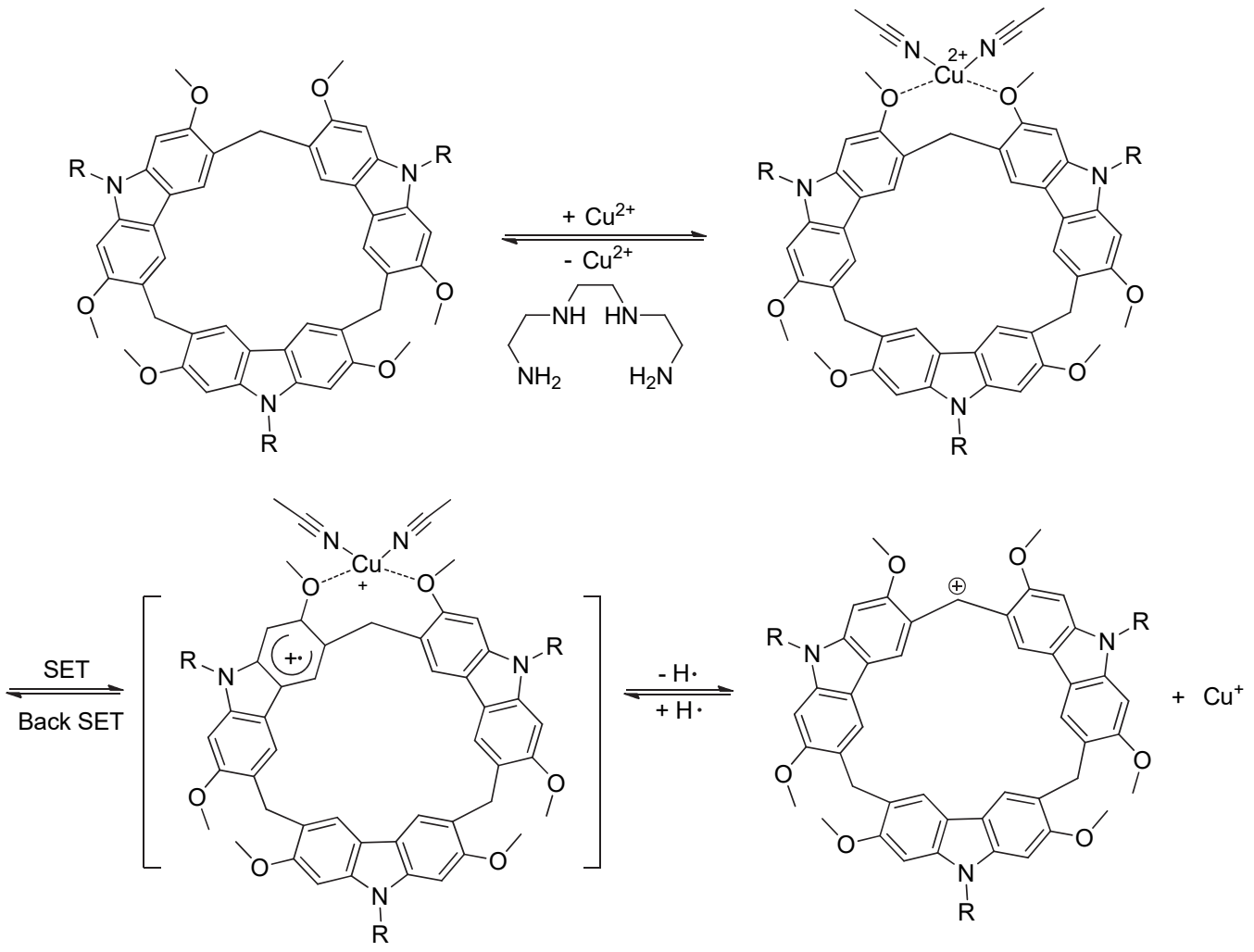

图式 29 杯 [3]咔唑的合成及其可能的 $\mathrm{C}-\mathrm{H}$ 活化机理

Scheme 29 Synthesis of calix[3]carbazole and proposed mechanism for the reversible $\mathrm{C}-\mathrm{H}$ activation

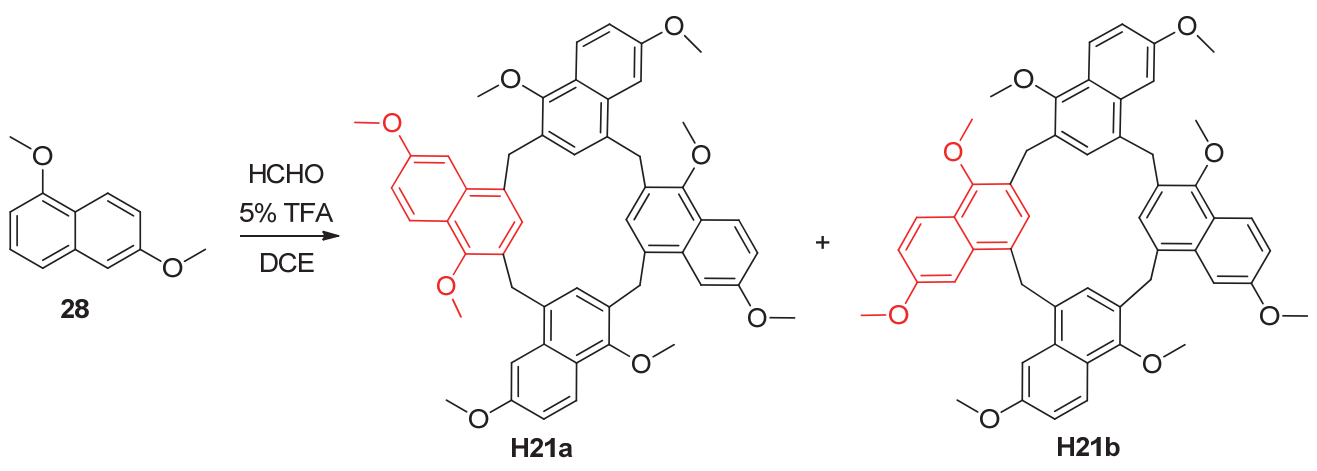

图式 30 杯[4]菜芳烃的合成

Scheme 30 Synthesis of calix[4]naphthalenes 
<smiles>COc1ccc2cc(C(C=O)(CCl)C(F)(F)F)ccc2c1</smiles>

29

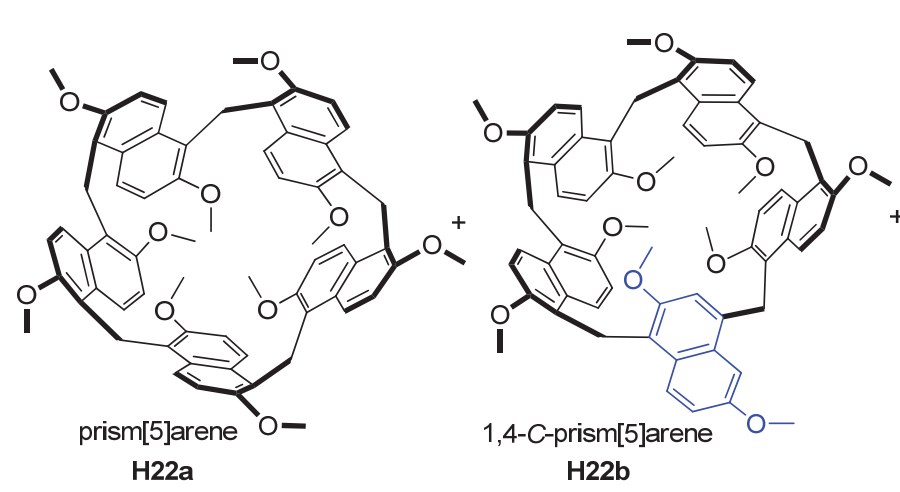

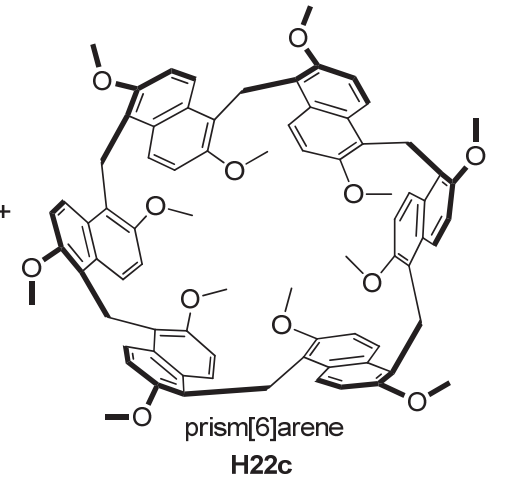

H22c

图式 31 棱芳烃的合成

Scheme 31 Synthesis of prism $[n]$ arenes

\section{6 基于葱环基元的大环芳烃}

\section{1 含葸杂 $[4]$ 芳烃}

通过 1,4,5,8-四甲氧基葱 31 和间二甲氧基苯 $\mathbf{3 0}$ 在 三氟乙酸催化下与甲醛缩合反应, Szumna 等 ${ }^{[66]}$ 得到两 个含有葱的杂 [4]芳烃 H23a 和 H23b (Anthracene-based Hybrid[4]arenes, Scheme 32). 该反应受热力学控制, 其 中 $\mathbf{H 2 3 a}$ 产率为 $10 \%$, 而 $\mathbf{H 2 3 b}$ 为痕量产物, 推测与其较 低的热力学稳定性有关. H23a 中的葸基元通过 Diels-
Alder 反应转化为刚性的三蝶烯基元，导致大环分子具 有增大的空腔.

\section{2 塔芳烃}

2,6-二甲氧基葱 32 是螺芳烃前体 2,6-二甲氧基三蝶 烯的合成原料 ${ }^{[32]}$. 最近, 我们 ${ }^{[67]}$ 研究发现 32 与多聚甲 醛在二氯甲烷中通过三氟乙酸催化缩合反应, 能够分别 以 $31 \%$ 与 $32 \%$ 产率得到两个新型大环芳烃 $\mathbf{H 2 4 a}$ 和 H24b (Scheme 33), 其中 H24a 中所有蒽单元通过 1,5 位

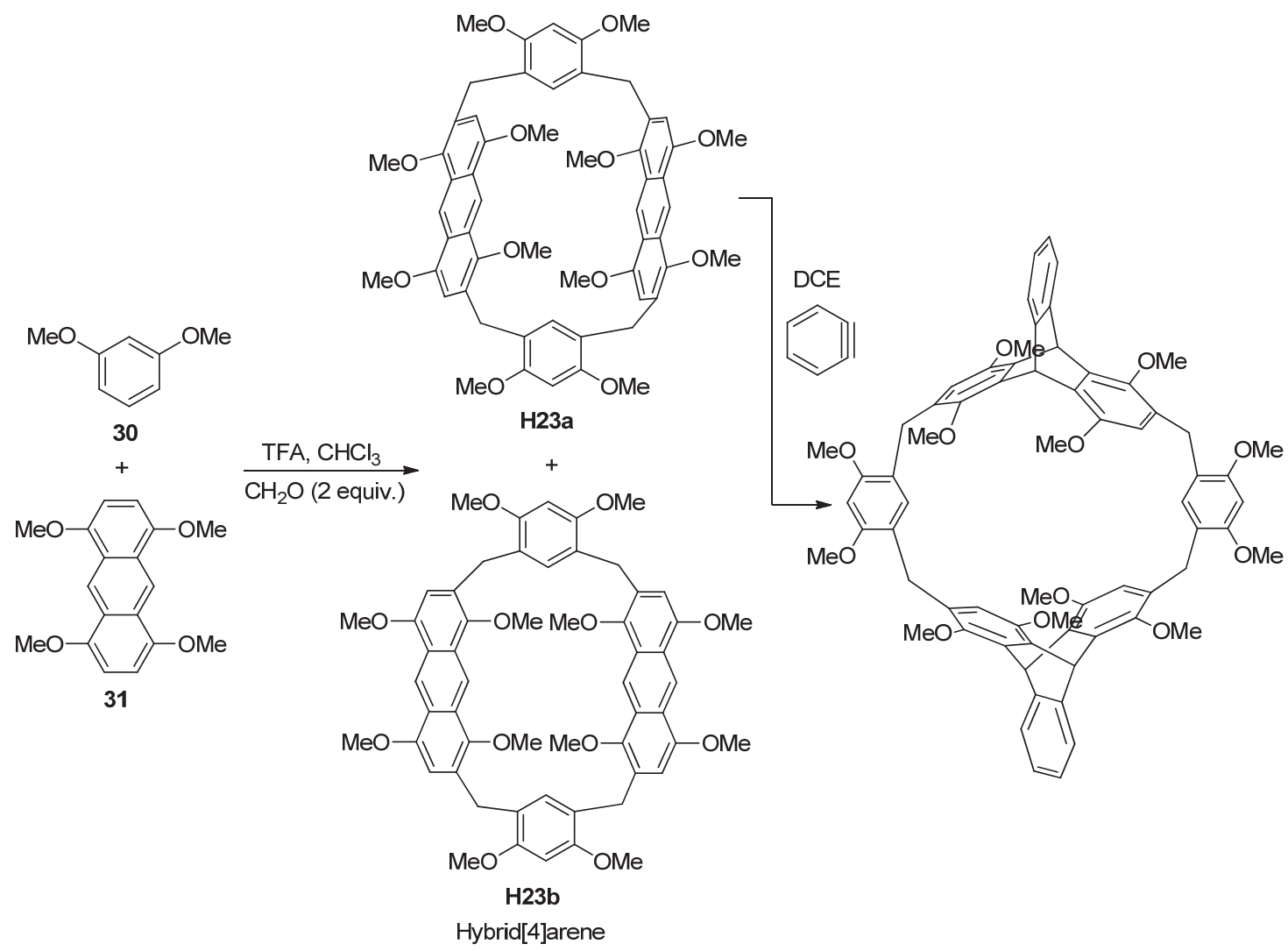

图式 32 含葱杂 [4]芳烃的合成及 H23a 的 Diels-Alder 反应

Scheme 32 Synthesis of anthracene-based hybrid[4]arenes and modification of H23a by the Diels-Alder reaction 
<smiles>COc1ccc2cc3ccc(OC)cc3cc2c1</smiles>

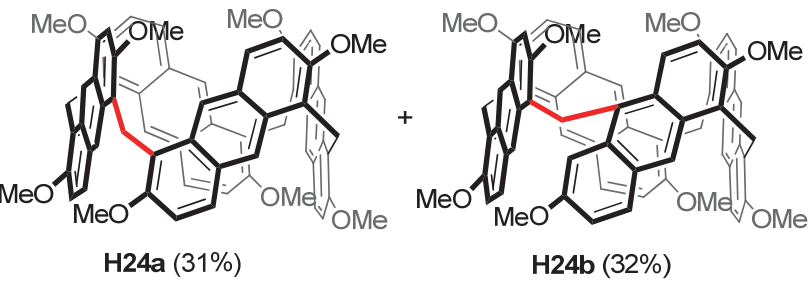

图式 33 塔[4]芳烃与异塔[4]芳烃的合成

Scheme 33 Synthesis of pagoda[4]arene and $i$-pagoda[4]arene

亚甲基桥连，而 $\mathbf{H 2 4 b}$ 中除一个亚甲基通过蒽单元的 1,10 位桥连, 其他亚甲基均通过葱单元的 1,5 位桥连. 由于这类大环芳烃具有类似于四方宝塔结构特征, 因而 命名为塔芳烃(Pagoda $[n]$ arenes), 其中 H24a 为塔[4]芳 烃, H24b 称为异塔[4]芳烃. 蒽的结构基元使得塔芳烃 大环不仅有着强的蓝色菼光性质, 而且具有固定的构象 及深的富电子空腔. 塔芳烃不仅可以在固态下包结正己 烷、一个或两个二氯甲烷分子, 而且能够与不同链长的 中性二腈分子以及广泛的含氮杂环盐客体形成稳定的 $1: 1$ 主客体络合物, 络合常数多数大于 $10^{3} \mathrm{~L} / \mathrm{mol}$, 有些 甚至高达 $10^{5} \mathrm{~L} / \mathrm{mol}$ 以上. 尤其是由于塔芳烃具有加深 的空腔结构, 因而随着二腈类客体烷基链长度的增加, 主客体间多重分子间相互作用逐渐加强, 主客体络合物 的络合常数从戍二腈到辛二腈增加显著. 此外, 由于塔 芳烃具有稳定的平面手性, 因此, 通过 HPLC 可以进一 步实现其有效拆分, 得到两对对映异构体. 对映异构体 的绝对构型通过 X 衍射单晶结构决定(图 5). 有趣的是 基于塔芳烃的对映异构体不仅显示镜像的 $\mathrm{CD}$ 信号, 而 且展现出强的圆偏振发光(CPL) 性质, 这是首例具有 CPL 性质的大环芳烃研究报道, 也使得它们在手性发光 材料中具有潜在的应用.

\section{7 结论与展望}

总结了过去十余年尤其是近年来人们发展的新型 大环芳烃分子，包括基于苯环基元的大环芳烃、基于三 蝶烯基元的大环芳烃、基于联苯基元的大环芳烃、基于 咔唑基元的大环芳烃、基于䒺环基元的大环芳烃以及基 于葱环基元的大环芳烃. 这些新型的大环芳烃分子不仅 易于合成, 具有特殊的结构, 而且显示广泛的主客体络 合性能. 尤其是有些大环芳烃还具有荧光或手性性质, 塔芳烃分子甚至具有强的 CPL 性质. 这些都使得新型 大环芳烃分子正逐渐发展成为一类重要的合成主体, 并 被广泛地应用于超分子组装、分子机器、吸附分离以 (a)
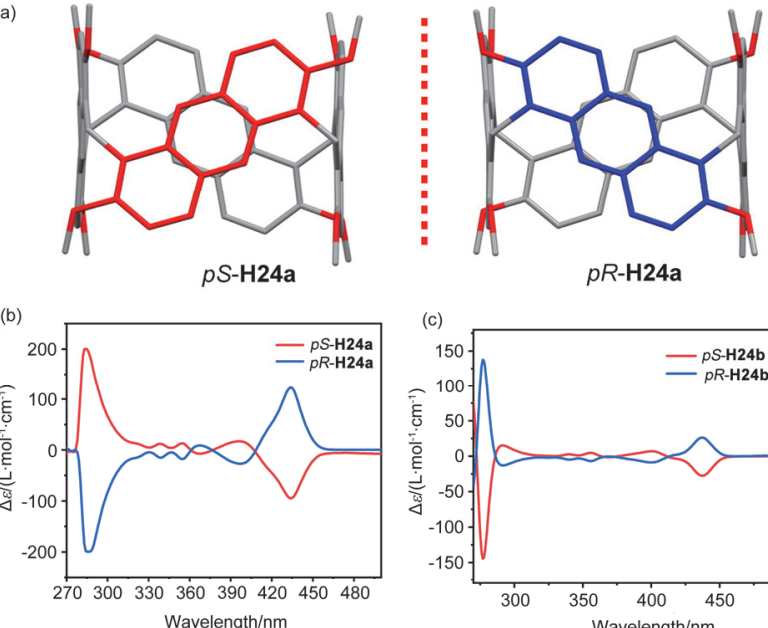

$p R-H 24 a$
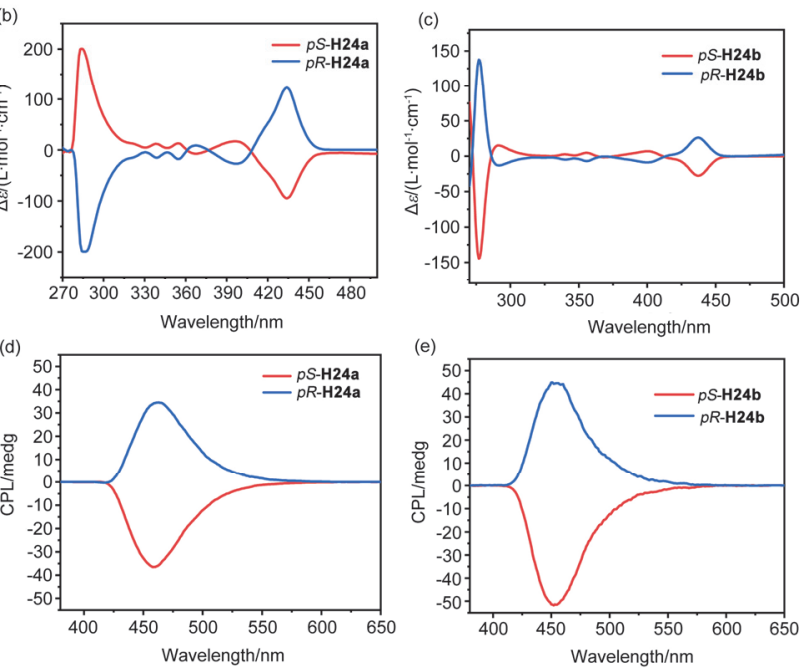

图 5 (a) $p S-\mathbf{H 2 4 a}$ 和 $p R-\mathbf{H 2 4 a}$ 的晶体结构, (b) $p S-\mathbf{H 2 4 a}$ 和 $p R-\mathbf{H 2 4 a} 、$ (c) $p S-\mathbf{H 2 4 b}$ 和 $p R-\mathbf{H 2 4 b}$ 的 $\mathrm{CD}$ 光谱，以及(d) $p S-H 24 \mathbf{a}$ 和 $p R-\mathbf{H 2 4 a} 、$ (e) $p S-\mathbf{H 2 4 b}$ 和 $p R-\mathbf{H 2 4 b}$ 的 CPL 光谱

Figure 5 (a) Crystal structures of $p S-\mathbf{H 2 4 a}$ and $p R-\mathbf{H 2 4 a}, \mathrm{CD}$ spectra of (b) $p S$-H24a and $p R$-H24a, (c) $p S-\mathbf{H 2 4 b}$ and $p R$-H24b, and CPL spectra of (d) $p S$-H24a and $p R$-H24a, and (e) $p S-\mathbf{H 2 4 b}$ and $p R-\mathbf{H 2 4 b}$

及苂光探针等领域中.

尽管大环芳烃化学得到了快速的发展, 各种不同类 型的新型大环芳烃分子不断地被报道，但是具有特殊光 电性质以及手性性质的大环芳烃分子体系依然有限，如 何实现新型大环芳烃分子的特殊功能与应用仍是难点. 可以相信新型大环芳烃以其特殊的结构和性质，必将受 到人们越来越大的关注与兴趣, 并在超分子化学、生物 医药以及功能材料等领域中显示出广泛的应用前景.

\section{References}

[1] Gutsche, C. D. Calixarenes Revisited, Royal Society of Chemistry, Cambridge, 1998.

[2] Sliwa, W.; Kozlowski, C. Calixarenes and Resorcinarenes: Synthesis, Properties and Applications, Wiley-VCH, Weinheim, Germany, 2009.

[3] Neri, P.; Sessler, J. L.; Wang, M.-X. Calixarenes and Beyond. Springer, Switzerland, 2016.

[4] Ogoshi, T.; Kanai, S.; Fujinami, S.; Yamagishi, T.-A.; Nakamoto, Y. J. Am. Chem. Soc. 2008, 130, 5022.

[5] Ogoshi, T. Pillararenes, The Royal Society of Chemistry, Croydon, UK, 2016.

[6] Chen, C.-F.; Han, Y. Acc. Chem. Res. 2018, 51, 2093.

[7] Schneebeli, S. T.; Cheng, C.; Hartlieb, K. J.; Strutt, N. L.; Sarjeant, A. A.; Stern, C. L.; Stoddart, J. F. Chem.-Eur. J. 2013, 19, 3860.

[8] Wang, J.-H.; Feng, H.-T.; Zheng, Y. S. Chem. Commun. 2014, 50, 11407. 
[9] Han, B.; Zhu, L.; Wang, X.; Bai, M.; Jiang, J. Chem. Commun. 2018, 54, 837 .

[10] Gao, B.; Tan, L.-L.; Song, N.; Li, K.; Yang, Y.-W. Chem. Commun. 2016, 52, 5804.

[11] Wu, J.-R.; Wang, C.-Y.; Tao, Y.-C.; Wang, Y.; Li, C.; Yang, Y.-W. Eur. J. Org. Chem. 2018, 1321.

[12] Dai, D.; Li, Z.; Yang, J.; Wang, C.; Wu, J.-R.; Wang, Y.; Zhang, D.; Yang, Y.-W. J. Am. Chem. Soc. 2019, 141, 4756.

[13] Boinski, T.; Cieszkowski, A.; Rosa, B.; Szumna, A. J. Org. Chem. 2015, 80, 3488 .

[14] Hua, B.; Shao, L.; Zhou, J.; Yu, G. New J. Chem. 2016, 40, 4756.

[15] Zafrani, Y.; Cohen, Y. Org. Lett. 2017, 19, 3719.

[16] Wu, J.-R.; Mu, A. U.; Li, B.; Wang, C.-Y.; Fang, L.; Yang, Y.-W. Angew. Chem., Int. Ed. 2018, 57, 9853.

[17] Wang, X.; Wu, J.-R.; Liang, F.; Yang, Y.-W. Org. Lett. 2019, 21, 5215 .

[18] Li, X.; Han, J.; Qin, J.; Sun, M.; Wu, J.; Lei, L.; Li, J.; Fang, L.; Yang, Y.-W. Chem. Commun. 2019, 55, 14099.

[19] Wu, J.-R.; Li, B.; Yang, Y.-W. Angew. Chem., Int. Ed. 2020, 59, 2251.

[20] Liu, Z.; Wu, J.; Wang, C.; Yang, J.; Wang, Y.; Yang, Y.-W. Chin. Chem. Lett. 2019, 30, 2299.

[21] Wu, J.-R.; Yang, Y.-W. J. Am. Chem. Soc. 2019, 141, 12280.

[22] Lei, S.-N.; Xiao, H.; Zeng, Y.; Tung, C.-H.; Wu, L.-Z.; Cong, H. Angew. Chem., Int. Ed. 2020, 59, 10059.

[23] Yang, W.; Samanta, K.; Wan, X.; Thikekar, T. U.; Chao, Y.; Li, S.; Du, K.; Xu, J.; Gao, Y.; Zuilhof, H.; Sue, A. C.-H. Angew. Chem., Int. Ed. 2020, 59, 3994.

[24] Chen, C.-F.; Ma, Y.-X. Iptycene Chemistry: From Synthesis to Applications, Springer-Verlag, Berlin Heidelberg, 2013.

[25] Han, Y.; Meng, Z.; Ma, Y.-X.; Chen, C.-F. Acc. Chem. Res. 2014, 47, 2026.

[26] Tian, X.-H.; Hao, X.; Liang, T.-L.; Chen, C.-F. Chem. Commun. 2009, 6771 .

[27] Tian, X.-H.; Chen, C.-F. Chem.-Eur. J. 2010, 16, 8072.

[28] Xia, Y.-X.; Xie, T.; Han, Y.; Chen, C.-F. Org. Chem. Front. 2014, 1, 140.

[29] Li, P.-F.; Chen, C.-F. Chem. Commun. 2011, 47, 12170.

[30] Tian, X.-H.; Chen, C.-F. Org. Lett. 2010, 12, 524.

[31] Xia, Y.-X.; Han, Y.; Chen, C.-F. Eur. J. Org. Chem. 2014, 1976.

[32] Zhang, G.-W.; Li, P.-F.; Meng, Z.; Wang, H.-X.; Han, Y.; Chen, C.-F. Angew. Chem., Int. Ed. 2016, 55, 5304.

[33] Wang, J.-Q.; Li, J.; Zhang, G.-W.; Chen, C.-F. J. Org. Chem. 2018, $83,11532$.

[34] Zhang, G.-W.; Li, P.-F.; Wang, H.-X.; Han, Y.; Chen, C.-F. Chem.Eur. J. 2017, 23, 3735.

[35] Zhang, G.-W.; Shi Q.; Chen, C.-F. Chem. Commun. 2017, 53, 2582.

[36] Shi, Q.; Han, Y.; Chen, C.-F. Chem.-Asian J. 2017, 12, 2576.

[37] Shi, Q.; Chen C.-F. Org. Lett. 2017, 19, 3175.

[38] Li, J.; Shi, Q.; Han, Y.; Chen, C.-F. Beilstein J. Org. Chem. 2019, 15,1795 .

[39] Zhang, G.-W.; Han, Y.-C.; Han, Y.; Wang, Y.-L.; Chen, C.-F. Chem. Commun. 2017, 53, 10433.
[40] Yang, X.; Mao, W.; Liu, Y.; Li, L.; Ma, D. Chin. J. Chem. 2019, 37 , 575.

[41] Guo, Y.; Han, Y.; Chen, C.-F. Front. Chem. 2019, 7, 543.

[42] Shi, Q.; Meng, Z.; Xiang, J.-F.; Chen, C.-F. Chem. Commun. 2018, 54, 3536.

[43] Zhou, H.-Y.; Han, Y.; Shi, Q.; Chen, C.-F. Eur. J. Org. Chem. 2019, 3406.

[44] Zhou, H.-Y.; Han, Y.; Shi, Q.; Chen, C.-F. J. Org. Chem. 2019, 84, 5872.

[45] Shi, Q.; Chen, C.-F. Chem. Sci. 2019, 10, 2529.

[46] Chen, H.; Fan, J.; Hu, X.; Ma, J.; Wang, S.; Li, J.; Yu, Y.; Jia, X.; Li, C. Chem. Sci. 2015, 6, 197.

[47] Zhou, J.; Yu, G.; Shao, L.; Hua, B.; Huang, F. Chem. Commun 2015, 51, 4188 .

[48] Ma, J.; Deng, H.; Ma, S.; Li, J.; Jia, X.; Li, C. Chem. Commun. 2015, 51, 6621.

[49] Zhou, J.; Yang, J.; Zhang, Z.; Yu, G. RSC Adv. 2016, 6, 77179.

[50] Ma, S.; Chen, H.; Li, J.; Jia, X.; Li, C. Chem. Asian J. 2016, 11, 3449.

[51] Ma, J.; Meng, Q.; Hu, X.; Li, B.; Ma, S.; Hu, B.; Li, J.; Jia, X.; Li, C. Org. Lett. 2016, 18, 5740.

[52] Dai, L.; Ding, Z.-J.; Cui, L.; Li, J.; Jia, X.; Li, C. Chem. Commun. 2017, 53, 12096.

[53] Huang, X.; Zhang, X.; Qian, T.; Ma, J.; Cui, L.; Li, C. Beilstein J. Org. Chem. 2018, 14, 2236.

[54] Wang, Y.; Xu, K.; Li, B.; Cui, L.; Li, J.; Jia, X.; Zhao, H.; Fang, J.; Li, C. Angew. Chem., Int. Ed. 2019, 58, 10281.

[55] Li, B.; Wang, B.; Huang, X.; Dai, L.; Cui, L.; Li, J.; Jia, X.; Li, C. Angew. Chem., Int. Ed. 2019, 58, 3885.

[56] Xu, K.; Zhang, Z.-Y.; Yu, C.; Wang, B.; Dong, M.; Zeng, X.; Gou, R.; Cui, L.; Li, C. Angew. Chem., Int. Ed. 2020, 59, 7214.

[57] Zhou, J.; Yang, J.; Hua, B.; Shao, L.; Zhang, Z.; Yu, G. Chem. Commun. 2016, 52, 1622.

[58] Zhou, J.; Yu, G.; Li, Q.; Wang, M.; Huang, F. J. Am. Chem. Soc. 2020, 142, 2228.

[59] Yang, P.; Jian, Y.; Zhou, X.; Li, G.; Deng, T.; Shen, H.; Yang, Z.; Tian, Z. J. Org. Chem. 2016, 81, 2974.

[60] Li, G.; Zhao, L.; Yang, P.; Yang, Z.; Tian, Z.; Chen, Y.; Shen, H.; Hu, C. Anal. Chem. 2016, 88, 10751.

[61] Zhou, X.; Li, G.; Yang, P.; Zhao, L.; Deng, T.; Shen, H.; Yang, Z.; Tian, Z.; Chen, Y. Sens. Actuators B 2017, 242, 56.

[62] Li, G.; Song, X.; Yu, H.; Hu, C.; Liu, M.; Cai, J.; Zhao, L.; Chen, Y.; Yang, P. Sens. Actuators B 2018, 259, 177.

[63] Yang, Z.; Chen, Y.; Li, G.; Tian, Z.; Zhao, L.; Wu, X.; Ma, Q.; Liu, M.; Yang, P. Chem.-Eur. J. 2018, 24, 6087.

[64] Boinski, T.; Cieszkowski, A.; Rosa, B.; Lesniewska, B.; Szumna, A. New J. Chem. 2016, 40, 8892.

[65] Sala, P. D.; Regno, R. D.; Talotta, C.; Capobianco, A.; Hickey, N.; Geremia, S.; Rosa, M.D.; Spinella, A.; Soriente, A.; Neri, P.; Gaeta, C. J. Am. Chem. Soc. 2020, 142, 1752.

[66] Boinski, T.; Szumna, A. New J. Chem. 2017, 41, 3387.

[67] Han, X.-N.; Han, Y.; Chen, C.-F. J. Am. Chem. Soc. 2020, 142, 8262. 